\title{
Linear Beta Pricing with Inefficient Benchmarks in a Given Factor Structure
}

George Diacogiannis* and Christos loannidis**

* Department of Financial Management and Banking, University of Piraeus, Greece, Tel: +30-210-414-2189, email: gdiacogiannis@gmail.com

**Corresponding author: Aston Business School, Aston University, UK. Tel: +44-121-204-3298 Email: c.ioannidis@aston.ac.uk 


\begin{abstract}
We show the equivalence between the zero-beta version of a multi-factor arbitrage pricing model and a linear pricing model utilizing undiversified inefficient benchmarks in a given factor structure. The resulting linear model is a two-beta model, with one beta related to the inefficient benchmark and another adjusting for its inefficiency. This linear model shows that there are only two distinctive and computable sources of risk, affecting security expected returns, despite the existence of several risk factors. In a short empirical example we demonstrate that the model can be employed to provide guidance and allow researchers to test for the validity of their selection of the underlying risk factors driving variations in security returns.
\end{abstract}

JEL Classification: G11, G12 
The objective of this paper is to show the equivalence between the zero-beta version of a multi-factor Arbitrage Pricing Model (APM) and a linear pricing model utilizing inefficient benchmarks in a given factor structure. This is motivated by the empirical evidence indicating the rejection of the expected return-standard deviation efficiency for various benchmarks, used in asset pricing models, as well as by the existence of multi-factor arbitrage pricing models. The resulting linear model is a twobeta model, with one beta related to the inefficient benchmark and another adjusting for its inefficiency. By exploring the relationship between the APM and a linear pricing model using inefficient benchmarks our results can be seen as closing a gap in the theoretical literature which has explored the relationship between the APM and a linear pricing model based on efficient benchmarks.

Various researchers attempted to empirically investigate the validity of the Capital Asset Pricing Model (CAPM) and the accumulated evidence revealed that differences in expected returns are not completely explained by differences in betas. ${ }^{1}$ In an important theoretical contribution Roll (1977) presented the equivalence between the CAPM and the market portfolio's expected return-standard deviation efficiency and forcefully argued that the CAPM is not testable because the true market portfolio is empirically unobservable ${ }^{2}$. Roll's equivalence argument also holds when utilizing a given expected return-standard deviation efficient benchmark ${ }^{3}$ other than the global minimum variance portfolio (GMVP). In this instance, a linear beta pricing relation based on this efficient benchmark is generated (the acronym LBPE: Linear Beta Pricing Efficient, was used) with observed data rather than the notional "market portfolio." Thus, in view of Roll's (1977) discussion, the inadequacy of the LBPE to

\footnotetext{
${ }^{1}$ For example, the following studies do not support the expected return-beta exact relation with a riskless asset: Black, Jensen and Scholes (1972); Blume and Friend (1973); Fama and MacBeth (1973); Jobson and Korkie (1982); Gibbons (1982); Stambaugh (1982); Jobson and Korkie (1985); Kandel and Stambaugh (1987); Shanken (1985); Shanken (1987); Gibbons, Ross and Shanken (1989); Green (1990); Zhou (1991); MacKinlay and Richardson (1991); Hawawini (1993) and Fletcher (1994). The zero-beta version of the expected return-risk exact relation was supported by Stambaugh, (1982) and rejected by Gibbons (1982) and Shanken (1985). A review of the statistical methods that have been employed to test the mean-standard deviation efficiency of a portfolio is provided by Kandel and Stambaugh (1989) and Shanken (1996).

${ }^{2}$ Ross (1977) and Fama (1977) have also demonstrated the equivalence between the CAPM and the expected return -standard deviation efficiency of the market portfolio.

${ }^{3}$ The term benchmark is used to indicate an 'index' or a 'market proxy'.
} 
account for security mean returns immediately implies the mean-standard deviation inefficiency of the chosen benchmark (see also Roll and Ross (1994)) ${ }^{4}$.

Ross' (1976a, 1976b) seminal contribution was the development of the APM, which constitutes one of the primary alternatives to the CAPM. In the absence of arbitrage opportunities in large economies and under the assumption that the stochastic return generating process is a multi-factor model, the APM asserts that the single-period expected return on a security could be approximately and linearly related to its betas relative to several risk factors ${ }^{5}$. Even though the APM offers a theoretical framework to determine the security expected returns, it does not provide any idea about the number of factors and their identity. The literature offers several empirical tests revealing the existence of various factors affecting security returns. However, there is no uniformity across various empirical arbitrage pricing models. Factors may vary across samples of securities, and consequently, a different model might have to be produced for each sample ${ }^{6}$.

There is one important point arising from this discussion: there is strong empirical evidence contradicting the prediction of the LBPE either by using a direct test for its validity or by empirically demonstrating that the cross-section of security mean returns can be explained by a number of factors. Market betas do not provide the predictive power to adequately explain average security returns which in turn implies the meanstandard deviation inefficiency of the selected benchmark. With these results in mind, the main objective of this paper is to provide a common ground between the APM and inefficient benchmarks in a given factor structure. More specifically we demonstrate the equivalence between the zero-beta version of a multi-factor APM and a linear pricing model employing inefficient benchmarks in a given factor structure.

\footnotetext{
${ }^{4}$ The portfolio frontier in the expected return-standard deviation space is the locus of minimum standard deviation portfolios of risky securities for all expected returns. We use the term 'inefficient' benchmark to indicate a 'non-frontier' benchmark, noting that the LBPE is also valid for frontier portfolios that lie on the negatively sloped segment of the expected return-standard deviation frontier. 5 The APM of Ross was extended further by numerous researchers including Huberman (1982); Chamberlain and Rothschild (1983); Chen and Ingersoll (1983); Dybvig (1983); Ingersoll (1984); Connor (1984); Connor and Korajczky (1988) and Lehmann and Modest (1988). An extension of the APM to an international setting was provided by Ross and Walsh (1983) and Solkin (1983).
}

${ }^{6}$ Sharpe (1977); Grinblatt and Titman (1983); Connor (1984); Kim and Wu(1987) and Ehrhardt (1987) offered linear multi-beta interpretations of equilibrium models in discrete time. 
Furthermore, several studies explored the relationship between the APM and the expected return-variance portfolio efficiency. Among the research in this direction are the studies by Dybvig and Ross (1985), Chamberlain (1983), Chamberlain and Rothschild (1983), Jobson and Korkie (1985), Grinblatt and Titman (1987), and Huberman, Kandel, and Stambaugh (1987). More specifically, Dybvig and Ross (1985) showed that if security returns are generated by a linear factor model, the CAPM implies the APM. Chamberlain (1983) concluded that if a linear combination of factor portfolios converges to a mean-variance efficient portfolio as the number of securities reaches infinity, then the APM holds. Grinblatt and Titman (1987) investigated K portfolios that can be used as proxies for the factors in the APM and showed the equivalence between the exact APM and the mean-variance efficiency of a portfolio that is a linear combination of these $\mathrm{K}$ portfolios. Hence, they showed that the results derived by Chamberlain (1983) for an infinite economy also hold for a finite set of assets. In a subsequent study, Jobson and Korkie (1985) considered the case in which factors can be represented as portfolio returns. They showed that exact arbitrage pricing implies that the portfolio on the efficient frontier at the point where the line from the risk-free rate is tangent to the efficient frontier is a portfolio of these factors. Further, Huberman, Kandel, and Stambaugh (1987) used mimicking portfolios as factor proxies, and they proved that the APM is equivalent to the statement that a combination of factor portfolios lies on the efficient frontier. Finally, Jobson and Korkie (1982), Gibbons, Ross, and Shanken. (1989), and Kandel and Stambaugh (1989), among others, developed tests for multi-index pricing models based on mean variance efficiency. The idea that a combination of factor portfolios is minimum variance efficient is explored earlier by Grinblat and Titman (1987). Fama (1996) calculates the weights for securities in multifactor-minimum-variance portfolio and argues that for the ICAPM to hold the 'market portfolio' must be multi-factor efficient. Ferson, Siegel, and Xu (2006) generalize the multi-factor-minimum-variance efficiency of Fama (1996) with conditional and unconditional mean-variance efficiency (Ferson and Siegel (2001)).

The APM framework and the analysis of expected return-standard deviation efficient or inefficient benchmarks seems to be inherently disjointed. However, common ground can be provided by considering multi-factor efficient or inefficient benchmarks in which the covariance matrix and the expected return vector of their securities have specific structures based on a multi-factor security return generating 
linear model. In this case it can be demonstrated an integration between the APM and the risk-expected return exact linear relations which are based on efficient and inefficient benchmarks in a given factor structure.

Based on the above mentioned empirical studies, two basic findings can be observed. First, there is a rejection of the validity of the LBPE for different benchmarks implying the mean-standard deviation inefficiency of each benchmark, and secondly, multi-factor pricing models exist that describe mean returns in which the selection of factors does not rely on a theoretical framework. Instead, in the latter, the factors are chosen by simple financial reasoning, plain intuition, or by their popularity among researchers. Given the results of these empirical studies our main objective is to develop a pricing model that is based on an observable inefficient benchmark in a given factor structure. This can be expanded to a multi-factor pricing model $^{7}$ in which the inefficient part of the particular benchmark constitutes a helpful norm for selecting common factors that affect security returns.

We demonstrate that for a multi-factor undiversified inefficient benchmark in a given factor structure, a multi-factor APM can be reduced to a linear two-beta model with one beta induced by the benchmark and one associated with the benchmark's inefficiency (LBPUI; Linear Beta Pricing Undiversified Inefficient). Thus we find that there are only two unique sources of risk, which driving variations in security expected returns, despite the existence of several risk factors. Perhaps most tellingly, the potential advantage of the LBPUI is that it can be employed with the addition of modifications to derive a multi-factor APM explaining security expected returns. Such a multi-factor APM is based on a theoretical framework because it employs a wellspecified model based on inefficient benchmarks. Additionally all factors are observable and they are proxies (apart from the benchmark) related to the inefficient part of the benchmark.

In summary the objective of the present work is to explore the relationship

\footnotetext{
${ }^{7}$ We use the name 'multi-factor arbitrage pricing model' to indicate that betas are measured against multiple specified factors.
} 
between the zero-beta version of a multi-factor APM and the LBPUI. More specifically, the equivalence between a multi-factor APM and the LBPUI is derived and the analysis can be considered an addition to the existing literature, which has only focused on the relationship between a multi-factor APM and a linear beta pricing model for a multi-factor efficient benchmark (LBPDE; Linear Beta Pricing

Diversified Efficient).A major implication is that the LBPUI can be employed as the formal foundation of multi-factor pricing models. This approach provides additional insights into the nature of the underlying risk factors that influence security expected returns. Finally, a multi-factor pricing model based on the LBPUI can be comprised of an observable premium related to a benchmark along with other observable factor premia related to the inefficiency of that benchmark. In this particular case, at least in theory, this multi-factor pricing model supports the survival of the benchmark's beta despite its inefficiency.

The remainder of the paper is organized as follows. Section II introduces the notation used. Section III provides an analysis for expected return-variance inefficient benchmarks in a given factor structure. In Section IV we describe the equivalence between a multi-factor APM and the LBPUI that holds for undiversified inefficient benchmarks in a given factor structure. In Section V we report and discuss the results from an empirical application of the methodology developed in this paper and compare them to those from a well-known three factor model. Finally Section VI presents our conclusions. All proofs are included in the appendices.

\section{Notation and assumptions}

Consider a perfectly competitive and frictionless market containing $N$ risky securities, where $N \geq 2$. Excluded from consideration are transaction costs and other market imperfections. It is assumed that investors have homogeneous beliefs that the single period random return of a simple asset (such as a single security) or composite (such as a given portfolio) $i$ can be expressed mathematically by the following linear $K$-factor $\operatorname{model}^{8}(\mathrm{~K}<<\mathrm{N})$ :

\footnotetext{
${ }^{8}$ In the paper we employ 'return' to briefly mean 'rate of return' and 'security' implying asset either simple or composite. 


$$
R_{i}=E\left(R_{i}\right)+b_{i 1} f_{1}+b_{i 2} f_{2}+\ldots+b_{i K} f_{K}+\varepsilon_{i}
$$

where $i=1,2, \ldots, N, E\left(R_{i}\right)$ is the unconditional expected return on security $i, f_{k}$ is the value of the $k^{\text {th }}$ factor that impacts the return on security $i, k=1,2, \ldots, K, b_{i k}$ denotes a measure of the sensitivity of the return on security $i$ to the fluctuations of the $k^{\text {th }}$ common factor, and $\varepsilon_{i}$ is the security i's idiosyncratic disturbance summarizing the effects not covered by the factors.

With no loss of generality, the number of securities $N$ is assumed to be much larger than the number of common factors $K$. Equation (1) can be normalized to make $E\left(f_{k}\right)=0$ for each $k$, and $E\left(\varepsilon_{\mathrm{i}}\right)=0$ for each $i$. In this framework, it is assumed that the variances of the common factors are well defined, $\sigma^{2}\left(f_{k}\right)=\sigma_{k}^{2}<\propto, k=1,2, \ldots, K$, the common factors are conditionally orthogonal, that is, $\operatorname{Cov}\left(f_{k}, f_{j}\right)=0 \quad k \neq j$, $k, j=1,2, \ldots, K$, and finally, the idiosyncratic disturbances are conditionally orthogonal to $f_{k}, k=1,2, \ldots, K$.

Beyond this, an additional assumption is that the idiosyncratic disturbance terms are uncorrelated across different securities, i.e. $E\left(\varepsilon_{i} \varepsilon_{j}\right)=\operatorname{Cov}\left(\varepsilon_{i}, \varepsilon_{j}\right)=0$, for all $i, j$ where $i \neq j^{9}$. This means that the covariance between the returns of two different securities is solely determined by their common dependence on the common factors, and the $N \times N$ covariance matrix $\mathrm{D}=E\left(\varepsilon^{\prime} \varepsilon\right)$ is diagonal, where $\varepsilon$ is the $N \times 1$ random vector of the idiosyncratic disturbances. The variances of the idiosyncratic disturbance terms are assumed to be bounded, that is $\sigma^{2}\left(\varepsilon_{i}\right) \leq \sigma^{2}<\propto, i=1,2, \ldots, N$ and $\sigma^{2}$ is a fixed positive number.

\footnotetext{
${ }^{9}$ Ross (1976a) assumes that the correlation between the idiosyncratic disturbance terms is zero (a strict factor model). The assumption of uncorrelated residuals was relaxed by Chamberlain and Rothschild (1983), in this case there is an approximate factor structure.
} 
In essence, Equation (1) shows that the return on a security $i$ can be decomposed into a part that is associated with $K$ common factors that capture all systematic risk and into another part due to the idiosyncratic disturbance term that is specific to security $i$ and reflecting risks specific to security $i$.

To this end, e was considered to be an $N \times 1$ vector of security expected returns, where its elements are assumed to be real finite numbers. In addition, it is assumed that security variances are real finite numbers and the $N \times \mathrm{N}$ variance-covariance matrix of all securities $\mathrm{V}$ is positive definite ${ }^{\mathbf{1 0}}$. This assumption implies that there are no redundant securities ${ }^{11}$. With the aid of Equation (1) the variance-covariance matrix $V$ in the multi-factor framework can be decomposed as follows:

$$
\mathbf{V}=\mathbf{V}_{f}+\mathbf{D}
$$

with $D$ the $N \times N$ diagonal matrix whose $\mathrm{i}^{\text {th }}$ bounded diagonal element is $\sigma^{2}\left(\varepsilon_{\mathrm{i}}\right)$, where $i=1,2, \ldots, N$, and $\mathrm{V}_{f}$ is the $\mathrm{N} \times \mathrm{N}$ matrix whose $(\mathrm{i}, \mathrm{j})$ element is given by:

$$
b_{i 1} b_{j 1} \sigma^{2}\left(f_{1}\right)+b_{i 2} b_{j 2} \sigma^{2}\left(f_{2}\right)+\ldots+b_{i K} b_{j K} \sigma^{2}\left(f_{K}\right)
$$

where the variances of security returns in relation to the $K$ factors appear along the diagonal ( $i=j=1,2, \ldots, N)$ and the covariances between security returns in relation to the $K$ factors appear in the off-diagonal elements $(i \neq j)$. It is assumed that the variances and covariances are well defined. In this formulation the variance of each security in addition to the idiosyncratic risk given by the elements of $D$ includes the products of the systematic risks across securities $b_{i K} b_{j K}$ times the volatility of the associated factor $\sigma^{2}\left(f_{K}\right)$. This implies that the variance of each security is constituted not only by its own measures of systematic risk but also by the same risk measures of the other securities under traded, thus moderating or increasing its own variability for any given factor volatility. In this case for a given security, even if its own systematic risk measure is small the impact on its variance will be amplified by the same measures of all other traded securities.

\footnotetext{
${ }^{10}$ In this paper vectors and matrices are typed in boldface straight font, and constants and variables are typed in straight font.

${ }^{11}$ A redundant security is the one whose return of a security can be generated by combining other securities.
} 
With this setting, consider a portfolio $q$ comprised of $\mathrm{N}$ securities. Portfolio $q$ is defined by an $N$ x 1 vector of proportions $\mathbf{X}_{q}$ invested in its securities with $\mathrm{X}_{q}^{\prime} \mathbf{u}=1$, where $\mathrm{u}$ is an $N \times 1$ vector of ones. Portfolio $q$ is well-diversified in a given factor structure if has no idiosyncratic risk. That is (a similar definition for a welldiversified portfolio is given by Wei (1988) and Huberman and Wang (2005)):

$$
\sigma^{2}\left(X_{q}^{\prime} \varepsilon\right)=0
$$

In this case portfolio $q$ contains only the risk related to the common factors and the linear relation between portfolio $q$ 's return and the associated $K$ common factors which influence it can be expressed as follows:

$$
R_{q}=E\left(R_{q}\right)+b_{q 1} f_{1}+b_{q 2} f_{2}+\ldots+b_{q K} f_{K}
$$

where $E\left(R_{q}\right)$ is the expected return on portfolio $q$, and $b_{q k}$ is the sensitivity of the portfolio $q$ 's return to the fluctuations in $k^{\text {th }}$ factor, $k=1,2, \ldots, K$. The APM of Ross (1976a, 1976b) assumes that the number of securities in the economy is sufficiently large so that the idiosyncratic risk can be eliminated in large portfolios.

Finally, a portfolio is said to be a multi-factor efficient or efficient in a given factor structure if no other portfolio with the same expected return can have a lower variance and no other portfolio with the same variance of return can have a higher expected return. Here, the covariance matrix $\mathrm{V}$ and the expected return vector $\mathrm{e}$ are produced using the $K$-factor security return generating model. All portfolios denoted on the expected return standard deviation space lying to the right of the minimum-variance portfolio set are defined as inefficient portfolios in a given factor structure.

\section{Expected return-variance inefficient benchmarks in a given factor structure}

The analysis begins by introducing the properties of the multi-factor, undiversified inefficient benchmarks. Consider a multi-factor, well-diversified efficient benchmark $q$ 
other than the GMVP. Let $p$ be a multi-factor, undiversified inefficient benchmark with $E\left(R_{p}\right)=E\left(R_{q}\right)$. In the expected return standard deviation space portfolio $p$ lies inside the frontier to the right of portfolio $q^{12}$. Then the return of portfolio $p$ can be decomposed into $R_{q}$ and a residual return $U_{p}$ :

$$
R_{p}=R_{q}+U_{p}
$$

where $E\left(U_{p}\right)=0$ holds. Later in this section we show that $U_{p}$ is the return of an arbitrage free portfolio and define its weights.

This decomposition is similar to those of Green (1986) (see Sec I, p. 297), Hansen and Richard (1987) (see Eq. [3.7], p. 596), Jagannathan (1996) (see Equation [1], p. 3) and Diacogiannis and Feldman (see Eq. [2], p. 9). Equation (5) implies $U_{p}=R_{p}-R_{q}$ which shows $U_{p}$ exists and is unique for every pair of returns $R_{p}$ and $R_{q}$

The linear relation between the $N \times 1$ vector of security expected returns and the $\mathrm{N} x 1$ vector of security betas in relation to the efficient benchmark $q$ is given by the Equation (6) below (proof in Appendix A, Equation (A9)):

$$
\mathbf{e}=E\left(R_{z q}\right) \mathbf{u}+\left[E\left(R_{q}\right)-E\left(R_{z q}\right)\right] \frac{\mathrm{VX}}{\sigma^{2}\left(R_{q}\right)}
$$

Pre-multiplying both sides of Equation (6) by $\mathrm{X}_{\mathrm{p}}^{\prime}$ and noting that $E\left(R_{p}\right)=E\left(R_{q}\right)$ we obtain:

$$
\sigma^{2}\left(R_{q}\right)=\operatorname{Cov}\left(R_{p}, R_{q}\right)
$$

Equation (7) shows that all the multi-factor inefficient benchmarks that have the same expected return with the efficient benchmark q have betas with respect to $q$ equal to 1 . Thus all the inefficient benchmarks that have the same expected return

\footnotetext{
${ }^{12}$ A detailed description of the properties and composition of an efficient benchmark in a given factor structure see Appendix A. For an examination of inefficient portfolios in an expected return-standard deviation framework see Diacogiannis (1999).
} 
with the efficient benchmark $q$ have the same beta with respect to that efficient benchmark.

Next we will derive the linear relation between the residual return $U_{p}$ and the $K$ common factors. Indeed we start by deriving, from Equation (5), the covariance between the return of the multi-factor inefficient benchmark $\mathrm{p}$ and the factor $f_{k}$, $k=1,2, \ldots, K$, as follows:

$$
\operatorname{Cov}\left(R_{p^{\prime}} f_{k}\right)=\operatorname{Cov}\left(R_{q}, f_{k}\right)+\operatorname{Cov}\left(U_{p^{\prime}} f_{k}\right)
$$

Dividing both sides of Equation (8) by $\sigma^{2}\left(f_{k}\right)$ results in:

$$
b_{p k}=b_{q k}+b_{U p k}
$$

Combining Equation (5) with Equation (4) establishes that:

$$
R_{p}=E\left(R_{q}\right)+b_{q 1} f_{1}+b_{q 2} f_{2}+\ldots+b_{q K} f_{K}+U_{p}
$$

Substituting Equation (9) into (10) becomes:

$$
R_{p}=E\left(R_{p}\right)+b_{p 1} f_{1}+b_{p 2} f_{2}+\ldots+b_{p K} f_{K}-b_{U p 1} f_{1}-b_{U p 2} f_{2}-\ldots-b_{U p K} f_{K}+U_{p}
$$

where $\operatorname{Cov}\left(f_{k^{\prime}}-b_{U p 1} f_{1}-b_{U p 2} f_{2}-\ldots-b_{U p K} f_{K}+U_{p}\right)=0, k=1,2, \ldots, K$

Note that $\operatorname{Cov}\left(f_{k^{\prime}},-b_{U p 1} f_{1}-b_{U p 2} f_{2}-\ldots-b_{U p K} f_{K}+U_{p}\right)=0$ implies ${ }^{b} U_{p} k=\frac{\operatorname{Cov}\left(U_{p}, f_{k}\right)}{\sigma^{2}\left(f_{k}\right)}$ for each $k$.

Equation (11) can be re-written as: 


$$
R_{p}=E\left(R_{p}\right)+b_{p 1} f_{1}+b_{p 2} f_{2}+\ldots+b_{p K} f_{K}+\varepsilon_{p}
$$

where

$$
\varepsilon_{p}=-b_{U p 1} f_{1}-b_{U p 2} f_{2}-\ldots-b_{U p K} f_{K}+U_{p}
$$

As can be observed, Equation (12) constitutes the $K$-factor return generating model for the return $R_{p}$ of the multi-factor, undiversified inefficient benchmark $p$ and it is consistent with the decomposition shown in Equation (5).

To gain further insight into the relation between $U_{p}$ and its betas, Equation (13) can be expressed as follows:

$$
U_{p}=b_{U p 1} f_{1}+b_{U p 2} f_{2}+\ldots+b_{U p K} f_{K}+\varepsilon_{p}
$$

At first glance, Equation (14) shows that $U_{p}$ is generated by $K$ factors and the portfolio $p$ 's idiosyncratic disturbance.

Equations (4), (7), (9), (12), and (14) can be used to show that the residual term is uncorrelated with the rate of return of the multi-factor efficient benchmark $q$, (proof in Appendix B):

$$
\operatorname{Cov}\left(R_{q}, U_{p}\right)=0
$$

By taking Equation (15) into account, Equation (5) expresses an orthogonal decomposition of the return of the multi-factor inefficient benchmark $p$. As Equation (5) can be also written as, $R_{p}=E\left(R_{p}\right)+\left(R_{q}-E\left(R_{q}\right)\right)+U_{p}$, where $E\left(R_{p}\right)=E\left(R_{q}\right)$, this implies that the beta of the inefficient benchmark $p$ with respect to the efficient benchmark $q$ is one, $\operatorname{Cov}\left(R_{q}-E\left(R_{q}\right), U_{p}\right)=0$, and $E\left(U_{p}\right)=0$ This is a linear return generating process for multi-factor, undiversified inefficient benchmarks that have expected returns equal to that of the multi-factor, well-diversified efficient benchmark $q$. 
The apparatus needed to define the variance of multi-factor inefficient benchmark $p$ has now been obtained. Indeed, using Equations (5) and (15), this variance can be expressed as follows:

$$
\sigma^{2}\left(R_{p}\right)=\sigma^{2}\left(R_{q}\right)+\sigma^{2}\left(U_{p}\right)
$$

where $\sigma^{2}\left(U_{p}\right)=$ the variance of $U_{p}$.

Equation (16) decomposes the variance of the inefficient benchmark $p$ into two parts; the variance of the multi-factor, well-diversified efficient benchmark $q$ and the variance of $U_{p}$. The lower the variance of $U_{p}$, the closer the position of the inefficient benchmark $p$ to the efficient benchmark $q$.

To develop intuition for the covariance between the return of any security, say $i$, and the return of the multi-factor inefficient benchmark p, Equation (5) is used to produce:

$$
\operatorname{Cov}\left(R_{i}, R_{p}\right)=\operatorname{Cov}\left(R_{i}, R_{q}\right)+\operatorname{Cov}\left(R_{i}, U_{p}\right)
$$

From Equation (17) it can be seen that the covariance between the returns of a security $i$ and the return of the inefficient benchmark $p$ is divided in two parts. The first part is the covariance between the returns of the security $i$ and the return of the welldiversified efficient benchmark $q$ and the second part is covariance between the return of the security $i$ and $U_{p}$. Equation (17) can be used together with Equation (6) to generate the asset allocation of the multi-factor inefficient benchmark $p$. Thus we have the following corollary.

Corollary III.1 The $N$ x 1 vector of proportions that define a multi-factor inefficient benchmark p can be written as follows:

$$
\mathrm{X}_{\mathrm{p}}=\frac{a-b E\left(R_{p}\right)}{a c-b^{2}} \mathrm{~V}^{-1} \mathrm{u}-\frac{b-c E\left(R_{p}\right)}{a c-b^{2}} \mathrm{~V}^{-1} \mathbf{e}+\mathrm{V}^{-1} \mathrm{~h}_{\mathrm{p}}
$$


where $\mathrm{h}_{\mathrm{p}}$ is the $N \times 1$ vector of covariances between the security returns and the residual term $U_{p}$.

(proof in Appendix B)

From Equation (18) we derive $u^{\prime} V^{-1} h_{p}=0$ and $e^{\prime} V^{-1} h_{p}=0$. Thus, the portfolio that is defined by the investment proportions vector $\mathrm{V}^{-1} \mathrm{~h}_{\mathrm{p}}$ is an arbitrage free portfolio. Now Equation (18) formally states that the investment proportion vector that defines a multi-factor inefficient benchmark can be decomposed into the investment proportions vector that defines a well-diversified frontier benchmark having the same expected return as the inefficient benchmark and an investment proportion vector that defines an arbitrage free portfolio.

\section{A Multi-factor APM using an undiversified inefficient benchmark in a given factor structure (LBPUI)}

In this section we describe the equivalence between a multi-factor APM and the LBPUI that holds for undiversified inefficient benchmarks in a given factor structure. The following corollary makes use of the preceding analysis and provides the main result of this section.

Corollary IV.1 Consider a perfectly competitive and frictionless market containing $\mathrm{N}$ securities, where short sales of securities are permitted and there are no arbitrage opportunities. It is assumed that investors believe that the single-period random return of any of the $\mathrm{N}$ securities can be generated by a linear $K$-factor model. Let $\mathrm{V}$ be a non-singular positive definite covariance matrix, and assume that there are at least two securities with different expected returns. Then, the following two propositions are equivalent ${ }^{13}$ :

\footnotetext{
${ }^{13}$ Chamberlain (1983) considered a riskless security and offered some bounds on the approximation error in the arbitrage pricing equation. Then he showed that these bounds imply the equivalence between exact arbitrage pricing and a well-diversified mean-variance efficient portfolio.
} 
(i) There is an exact relation between the vector of expected security returns and the K vectors of factor betas:

$$
\mathbf{e}=\lambda_{O} \mathbf{u}+\lambda_{1} \mathrm{~B}_{1}+\lambda_{2} \mathrm{~B}_{2}+\ldots+\lambda_{K} \mathrm{~B}_{\mathbf{K}}
$$

Where $\mathrm{B}_{1}, \mathrm{~B}_{2}, \ldots, \mathrm{B}_{\mathbf{K}}$ are the $N \times 1$ vectors of factor beta coefficients of the securities on the K factors.

(ii) The vector of security expected returns can be expressed as follows ${ }^{14}$

$$
\mathbf{e}=E\left(R_{\mathrm{zp}} \boldsymbol{\mu}+\left[E\left(R_{p}\right)-E\left(R_{z p}\right)\right] \frac{\mathrm{VX}_{\mathrm{p}}}{\sigma^{2}\left(R_{q}\right)}-\left[E\left(R_{p}\right)-E\left(R_{z p}\right)\right] \frac{\mathrm{h}_{\mathrm{p}}}{\sigma^{2}\left(R_{q}\right)}\right.
$$

where $\mathbf{X}_{\mathrm{p}}^{\prime} \mathrm{u}=1, E\left(R_{\mathrm{Zp}}\right)=$ the expected return of a well-diversified frontier portfolio whose return is uncorrelated ${ }^{15}$ with the return of the multi-factor inefficient portfolio $p, E\left(R_{p}\right)=E\left(R_{q}\right)$, the efficient benchmark $q$ is other than the GMVP, $\sigma^{2}\left(R_{q}\right)=$ the variance of returns on the multi-factor well-diversified minimum variance portfolio $q$, and $\mathrm{h}_{\mathrm{p}}=$ the $N \mathrm{x} 1$ vector of covariances between the security returns and the residual term ${ }^{16}$.

\section{(Proof in Appendix B)}

\footnotetext{
${ }^{14}$ Diacogiannis and Feldman (2013) derived a similar result as that of Equation (19) using an expected return-standard deviation framework, where the covariance matrix is not required to have any particular structure.

${ }^{15}$ We know that all portfolios that have expected returns equal to that of $\mathrm{zq}$ are uncorrelated with $\mathrm{q}$. This implies that the minimum variance portfolio $\mathrm{zq}$ is uncorrelated with all portfolios that have the same expected return with q. Since $E\left(R_{p}\right)=E\left(R_{q}\right)$, benchmark p is uncorrelated with zq. Hence $E\left(R_{z q}\right)=E\left(R_{z p}\right)$. Any inefficient benchmark has infinitely many zero beta portfolios at all levels of expected returns. So if the inefficient benchmark $p$ has the same expected return with the frontier portfolio zp, Equation (20) becomes a zero relation (see for a detailed analysis in an expected returnvariance framework Diacogiannis and Feldman (2013)). Here we assume that $E\left(R_{z p}\right)$ is given by Equation (A11) in Appendix A with $E\left(R_{p}\right)=E\left(R_{q}\right)$ and $z p$ is a well-diversified minimum variance portfolio.

${ }^{16}$ Green (1986) examined the consequences of inefficient portfolios on deviations from the security market line. Ferguson and Shockley (2003) showed that the exclusion of 'debt' from the market portfolio produces understated betas.
} 
To obtain further understanding of the expected return-risk relation, Equation (20) can be used to express security expected returns in terms of betas with respect to the multi-factor, undiversified inefficient benchmark $p$ as follows (LBPUI):

$$
\mathbf{e}=E\left(R_{z p} \boldsymbol{\psi}+\left[E\left(R_{p}\right)-E\left(R_{z p}\right)\right] \frac{\sigma^{2}\left(R_{p}\right)}{\sigma^{2}\left(R_{q}\right)} \mathbf{B}_{\mathrm{p}}-\left[E\left(R_{p}\right)-E\left(R_{z p}\right)\right] \frac{\sigma^{2}\left(U_{p}\right)}{\sigma^{2}\left(R_{q}\right)} \mathbf{B}_{U p}\right.
$$

where $\mathrm{B}_{\mathrm{p}}$ is the $N \times 1$ vector of security betas in relation to the multi-factor inefficient benchmark $p$, and $\mathrm{B}_{\mathbf{U}}$ is the $\mathrm{N} \times 1$ vector of security betas in relation to $U_{p}$.

Undoubtedly, the linear model summarized in Equation (21) shows that the betas of the benchmark alone do not sufficiently explain security expected returns. More prominently, the multi-factor APM can be represented by a two-beta model that accounts for security expected returns. One induced by the inefficient benchmark and the other adjusting for its inefficiency. This is an intuitively appealing result. Even in the presence of several sources of factor risks, surprisingly, there are only two unique sources of risk that influence expected returns.

In addition, from Corollary IV.1, it can be seen that the validity of Equation (20) and the assumption that security returns obey a linear $K$-factor model imply the existence of a multi-factor APM. Apparently, this provides another approach to derive a multi-factor APM. Such a model is produced by applying a linear $K$-factor return generating model to Equation (20), which in turn relies on the multi-factor inefficiency of a non-diversified benchmark.

It is interesting to note here that Equation (20) can also be derived using conditions that preclude arbitrage opportunities. The basic logic of this approach is as follows. Using Corollary III.1 to write $\mathbf{X}_{\mathbf{p}}=\mathbf{X}_{\mathbf{q}}+\mathbf{X}_{U \mathbf{p}}$, with $\mathbf{X}_{\mathbf{q}}$ denoting the $N \times 1$ vector of proportions that define the multi-factor efficient benchmark $q$, where $E\left(R_{q}\right)=E\left(R_{p}\right)$, and $\mathrm{X}_{\mathrm{Up}}$ is the $N \times 1$ proportions vector defining an arbitrage free 
portfolio, that is $\mathbf{X}_{U p}^{\prime} \mathbf{u}=0$. After a pre-multiplication of $X_{p}=X_{q}+X_{U p}$ by $\mathbf{e}^{\prime}$ and noting that $E\left(R_{q}\right)=E\left(R_{p}\right)$ implies $\mathbf{X}_{U p}^{\prime} \mathbf{e}=0$. Finally, the condition $X_{U p}^{\prime}\left(V X_{p}-h_{p}=X_{U p}^{\prime} V X_{q}=0\right.$ holds, since the arbitrage free portfolio defined by the $\mathrm{N} \times 1 \mathrm{X}_{\mathrm{Up}}$ is orthogonal to the multi-factor efficient benchmark $q$. Thus, we see that $X_{U p}^{\prime}$ is orthogonal to the unit vector $u$ the vector of expected returns $e$ and the vector $V X_{p}-h_{p}$. As a consequence, the expected return vector can be represented as a linear combination of $\mathbf{u}$ and $\mathbf{V X} \mathbf{P}_{\mathrm{p}}-\mathrm{h}_{\mathrm{p}}$ which in turn implies Equation (20).

It is worth mentioning that taking the results of Corollary A.3 (see Appendix A) and Corollary IV.1 together, the multi-index APM is implied by assuming a linear $K$ factor generating model plus the validity of either the LBPDE or of the LBPUI. This clearly shows the flexibility of the multi-factor APM to hold under different sets of assumptions. It also means that either a multi-factor, well-diversified efficient benchmark or a multi-factor, undiversified inefficient benchmark whose return obeys a linear $K$-factor return generating model can be used to derive a multi-factor APM. In the latter case, however, an additional factor that is related to the inefficiency of the benchmark should be taken into account.

It is also worth noting that empirical investigations that employ inefficient benchmarks in a given factor structure should adopt Equation (21) (or Equation (20)) rather than the mis-specified equation (Equation A19) in Appendix A), which in this context is the LBPDE. In this case, it is the combination of Equation (21) with a multifactor return generating model that can provide the statistical structure for the testing of hypotheses regarding security returns. When a benchmark is multi-factor inefficient, employing LBPDE results in a misspecification of the equation used for estimation and testing. Basically, there are two sources of misspecification. The first potential source of misspecification results from omitting the additional beta related to the inefficiency of the benchmark. The second misspecification occurs because the LBPUI employs a 
weighted beta induced by the multi-factor inefficient benchmark, which differs from the unadjusted beta of the $\mathbf{L B P D E}^{17}$.

Although a multi-factor APM can also be derived without utilizing the LBPDE or the LBPUI (e.g., Ross (1976a, 1976b)), the previous analysis in this work has two notable uses. First, Corollary IV.1 (Corollary A.3 in Appendix A) explains the relationship between the LBPUI (LBPDE) and the multi-factor APM. Second, the key point is that the LBPUI (or LBPDE) can be utilized as the formal foundation of multifactor pricing models. It provides some guidance and permits researchers to select underlying risk factors that drive variations in security returns by examining the possible linear relationships between the second risk factor and observed variables.

Unfortunately, the arbitrage pricing theory does not provide any formal theoretical or empirical guidance for the identification or the selection of the underlying risk factors that drive variations in security returns. Accordingly, the exploration of the crosssectional predictability of security returns uses various predictor variables. For example, Chan, Hamao and Lakonishok (1991) used variables such as earnings yield, cash flow yield, size, and book to market ratio. Naranjo, Nimalendran and Ryngaert (1998) employed the dividend yield, etc. These variables appear to have been selected based on simple financial reasoning, by plain intuition, or by their popularity among researchers. Equation (21) constitutes a basis for selecting several factors that affect the risk related to the benchmark, the risk related to its inefficiency, or both. To illustrate, the second case is discussed. Using the security return generating model and Equation (14), the following can be obtained:

$$
\mathbf{B}_{U p}=b_{U p 1} \frac{\sigma^{2}\left(f_{1}\right)}{\sigma^{2}\left(U_{p}\right)} \mathbf{B}_{1}+\ldots+b_{U p K} \frac{\sigma^{2}\left(f_{k}\right)}{\sigma^{2}\left(U_{p}\right)} \mathbf{B}_{K}+\frac{1}{\sigma^{2}\left(U_{p}\right)} \mathbf{g}
$$

where $\mathbf{g}$ is the $\mathrm{N} \times 1$ column vector with elements $\operatorname{Cov}\left(R_{i}, \varepsilon_{i}\right), i=1,2,3, \ldots, \mathrm{N}$.

\footnotetext{
${ }^{17} \mathrm{Kim}$ and Wu (1987) tested a multi-factor equilibrium risk-return model that is derived by combining the CAPM and a multi-factor return generating model. They implicitly assumed in their tests that the proxy chosen for the market portfolio is ex-post efficient and no attempt was made to verify their assumption. As the present work shows, the inefficiency of a market index leads to misspecification of their model.
} 
The analysis presented also holds for both well-diversified and inefficient benchmarks. In the case of a well-diversified benchmark, in Equation (22) $\mathbf{g}=\mathbf{0}$, where 0 is the $\mathrm{N} x 1$ zero vector.

Next, substituting Equation (22) into Equation (21) gives ${ }^{18}$ :

$$
\begin{aligned}
\mathbf{e}=E\left(R_{\mathrm{zp}} \boldsymbol{\mu}+\left[E\left(R_{p}\right)-E\left(R_{z p}\right)\right] \frac{\sigma^{2}\left(R_{p}\right)}{\sigma^{2}\left(R_{q}\right)} \mathrm{B}_{\mathrm{p}}\right. & -\delta_{1} \frac{\sigma^{2}\left(U_{p}\right)}{\sigma^{2}\left(R_{q}\right)} \mathrm{B}_{1}-\ldots \\
& -\delta_{\mathrm{K}} \frac{\sigma^{2}\left(U_{p}\right)}{\sigma^{2}\left(R_{q}\right)} \mathrm{B}_{\mathrm{K}}-\delta_{\mathrm{K}+1} \mathbf{g}
\end{aligned}
$$

where $\delta_{k}=\left[E\left(R_{q}\right)-E\left(R_{z q}\right)\right] b_{U p k} \frac{\sigma^{2}\left(f_{k}\right)}{\sigma^{2}\left(U_{p}\right)}, k=1,2, \ldots, K$ and

$$
\delta_{\mathrm{K}+1}=\left[E\left(R_{q}\right)-E\left(R_{z q}\right)\right] \frac{1}{\sigma^{2}\left(U_{p}\right)}
$$

Upon reflection, Equation (23) provides a helpful norm for the factor selection that has remained unclear to date. It shows that the factors, other than the chosen benchmark, that influence security expected returns are proxies for the residual term derived from the multi-factor inefficiency of the chosen benchmark. Therefore, on the one hand, it focuses the researcher's attention not only on the security betas calculated against the benchmark but also on the betas of securities that are related to the inefficiency of the chosen benchmark. On the other hand, it provides flexibility because it permits researchers to select the factors that provide the best explanation for the inefficient part of the specific benchmark at hand.

It is reasonable to further this argument and state that the direct use of macroeconomic variables in the security return generating model is not appropriate due to the

\footnotetext{
${ }^{18}$ Wei (1988) developed a model that combined features of the CAPM and APM. His analysis is valid in a competitive equilibrium and his version of the APM included the market portfolio where it is assumed to have idiosyncratic risk in a given factor structure. His model included $k+1$ factors priced with the last factor being a beta due to the existence of the market portfolio's idiosyncratic risk.
} 
multicollinearity problems as well as to the lack of identification of the macroeconomic variables that influence security returns in advance. One way to proceed is to utilize the technique of principal components to construct independent factors from a set of macroeconomic variables. It is useful to point out that this procedure eliminates multicollinearity among the variables that explain security returns and also reduces the dimensions of this set of independent variables. Among the extracted variables, the variables that affect the risk due to the inefficiency of the chosen benchmark (market proxy) can be examined. Lastly, the conditions under which the risk prices take nonzero values can be investigated. A close inspection of Equations (23) and (24) reveals that the risk price associated with a factor other than the betas of the chosen benchmark is affected by the excess return on the benchmark over and above the return on a zerobeta portfolio, the betas of the securities on the $K$ factors, the betas of the securities in relation to $U_{p}$, and the two variances. Thus, a risk price is different from zero if the betas take values that are significantly different from zero.

It is interesting that Equation (23) is consistent with two basic empirical findings reported earlier: the acceptance of the expected return-standard deviation inefficiency for various benchmarks and the existence of multi-factor pricing models that characterize expected security returns. More significantly, Equation (23) provides a combination of the LBPUI and the return generating model and produces a testable pricing model. This model provides guidance regarding the risk premia and suggests searching for factors that explain a substantial fraction of the covariation between security returns and the residual term due to the multi-factor inefficiency of the benchmark. Furthermore, as only the available traded securities in the market can be used, Roll's (1977) critique is not applicable.

Although Equation (23) is supported by a well-specified theoretical foundation, it is not an equilibrium model. However, it is operational because it admits several risk sources that are related to the inefficiency of the given benchmark. In addition, it does not require the market portfolio, and it can be used in any market segment.

The theoretical APM, as developed by Ross (1976a, 1976b), does not make use of the market portfolio or a benchmark in the pricing equation. However Equation (23) 
unifies the basic ingredients of the multi-factor APM and the LBPUI and provides a model that takes the benchmark portfolio's beta into account as a factor that influences security expected returns. Therefore, at least in theory, the survival of the survival of the security betas in relation to the benchmark is supported.

Finally, additional differences between the APM developed by Ross (1976a, 1976b) and Equation (23) are described below. Equation (23) is an exact multi-factor APM, unlike the original APM that only approximately relates the security expected returns with factor betas. This latter model does not require a benchmark's beta to be used as a variable to explain security expected returns, while Equation (23) requires that the beta of a benchmark is included as an explanatory variable of security expected returns. In Equation (23), the benchmark portfolio's idiosyncratic risk is priced, whereas in the conventional APM, only factor betas are priced.

The original APM Ross (1976a) assumes the existence of several common factors but does not identify them, while Equation (23) asserts that the security betas with respect to a benchmark and the security betas with respect to factors that proxy the inefficiency of the benchmark influence security expected returns. Equation (23) constitutes a simple link among the single-period expected return-variance analysis and the single-period multi-factor pricing models. In Equation (23), each beta is multiplied by a ratio of two variances, while the APM uses unadjusted betas. Lastly, we can use Equation (21) and identify the factors that influence the risk related to the benchmark and have as an individual observable factor, the risk related to its inefficiency.

\section{An empirical application}

We evaluate the reliability of our approach by comparing the expected returns of a number of portfolios calculated using our methodology to the same predictions derived from a well-established linear multi-factor model. Our proposed methodology suggests that on the average the two 'equilibrium pricing' generating approaches should yield equivalent results. 
More specifically we apply our approach considering the monthly returns of the six value weighted portfolios formed on size and book-to-market, listed on the Kenneth French website ${ }^{19}$ along with the time series of the factor values covering the period $1926 \mathrm{~m} 7$ to $2018 \mathrm{~m} 8$, a time period of 1106 months. The six portfolios were created as follows. First, in June of each year $t$ the stocks are ranked on the basis of size. Then all the stocks are parted by the median into two groups, small (S) and big (B). The stocks are also divided into three book-to-market (B/M) equity groups. Low B/M group (L) contains stocks with $30 \%$ lowest $\mathrm{B} / \mathrm{M}$ ratio, medium $\mathrm{B} / \mathrm{M}$ group $(\mathrm{M})$ consists of stocks with $40 \%$ medium $\mathrm{B} / \mathrm{M}$ ratio and high $\mathrm{B} / \mathrm{M}$ group $(\mathrm{H})$ contains stocks with $30 \%$ highest $\mathrm{B} / \mathrm{M}$ ratio. Next, from the intersections of the two size groups with the three $\mathrm{B} / \mathrm{M}$ ratio groups six portfolios are constructed for each year, BH, BM, BL, SH, SM, SL (we call them p1,p2,p3,p4,p5.p6, respectively). The size factor SMB is calculated as the average return on the three small portfolios minus the average return on the three big portfolios. The value factor HML is calculated as the average return on the two value portfolios (high $\mathrm{B} / \mathrm{M}$ ratios) minus the average return on the two growth portfolios (low B/M ratios). The monthly value-weighted returns on the six portfolios are calculated from July of year $t$ to June of year $t+1$ and the portfolios are reformed in June of year $\mathrm{t}+1$.

The following linear three-factor model is utilized:

$$
p_{s, t}=a_{s}+b_{s} R_{m, t}+g_{s} S M B_{t}+h_{S} H M L_{t}+\varepsilon_{s, t}
$$

where $p_{s, t}$ is the realized return on portfolio $s(s=1,2,3,4,5,6)$ for month $t(t=$ $1,2,3, \ldots, 1106)$ and $a_{S}$ denotes the intercept. The risk factors are the following: $R_{m, t}$ is value-weighted return of all CRSP firms incorporated in the US and listed on the NYSE along with $S M B_{t}$ the difference of the returns on small firms and large firms for month $t$, and $H M L_{t}$ the difference in returns of firms with high $\mathrm{B} / \mathrm{M}$ ratios and the returns of firms with low $\mathrm{B} / \mathrm{M}$ ratios for month t. Parameters $b_{s}, g_{s}, h_{s}$ are measures

\footnotetext{
${ }^{19}$ We are grateful to Professor French for making these data available
} 
of the sensitivities of the returns on portfolio $s$ to changes on these three common risk factors and $\varepsilon_{s, t}$ a white noise error term of portfolio $s$ for month $t$.

Table 1 presents for each portfolio estimates of the three-factor time-series regression represented by Equation (25). All the estimated coefficients, except $\hat{g}_{S}$ for portfolio p6, are statistically significant at $1 \%$ level.

Table 1: The estimates of the three-factor time-series regressions for monthly returns on six portfolios formed on size and book-to-market ratio (1926m7-2018m9, p-values are in parentheses)

\begin{tabular}{|c|c|c|c|c|c|c|}
\hline & $\mathrm{p} 1$ & $\mathrm{p} 2$ & $\mathrm{p} 3$ & $\mathrm{p} 4$ & $\mathrm{p} 5$ & $\mathrm{p} 6$ \\
\hline \multirow{2}{*}{$\hat{a}_{S}$} & -0.17923 & 0.05419 & 0.01495 & 0.06899 & -0.05402 & -0.12533 \\
& $(0.00000)$ & $(0.08578)$ & $(0.49883)$ & $(0.00194)$ & $(0.15983)$ & $(0.00120)$ \\
\hline \multirow{2}{*}{$\hat{b}_{S}$} & 1.08859 & 0.98393 & 1.02320 & 1.02226 & 0.98591 & 1.08763 \\
& $(0.00000)$ & $(0.00000)$ & $(0.00000)$ & $(0.00000)$ & $(0.00000)$ & $(0.00000)$ \\
\hline \multirow{2}{*}{$\hat{g}_{S}$} & 1.03414 & 0.82088 & 0.92921 & -0.09068 & -0.13945 & 0.01431 \\
& $(0.00000)$ & $(0.00000)$ & $(0.00000)$ & $(0.00000)$ & $(0.00000)$ & $(0.25439)$ \\
$\hat{h}_{S}$ & -0.19068 & 0.29443 & 0.78597 & -0.23018 & 0.32673 & 0.79326 \\
& $(0.00000)$ & $(0.00000)$ & $(0.00000)$ & $(0.00000)$ & $(0.00000)$ & $(0.00000)$ \\
\hline & & & & & & \\
\hline $\mathrm{R}^{2}$ & 0,97454 & 0.97807 & 0.99209 & 0.98110 & 0.95061 & 0.96860 \\
\hline
\end{tabular}

After setting $R_{p, t}=R_{m, t}$, we use Equation (5) to calculate $U_{p, t}$, where $U_{p, t}=R_{p, t}-R_{q, t}, t=1,2,3 \ldots 1106$. We initially calculate the $(6 \times 1)$ mean-return vector (6 portfolios) using Equation (25). Subsequently we compute the $(6 \times 6)$ variance-covariance matrix V, following Equations (2) and (25).

We proceed by projecting the mean return of portfolio $p$ on the minimum variance portfolio set of the 6 portfolios and calculating the weights that define the minimum variance portfolio $q$, in effect creating the corresponding efficient benchmark $q$, where $\bar{R}_{p}=\bar{R}_{q}$. Then we use the weights of the minimum variance portfolio $q$ and the 
monthly returns of the six portfolios to calculate the monthly returns $R_{q, t}$ of portfolio q. We observe that portfolio $q$ has a mean return greater than the mean return of the GMVP, confirming that $\mathrm{q}$ is a mean-variance efficient portfolio. Finally, we calculate the monthly returns $U_{p, t}$ by subtracting for each month the return of the efficient portfolio $q$ from the corresponding return of the market index (Equation (5)) ${ }^{20}$.

Next we test for the statistical validity of the restrictions regarding the relationships between the risk metrics of the portfolios $p, q$ and the return $U_{p}$ (see Equations (15) and (16)). We find that the sample value of the correlation coefficient between $R_{p, t}$ and $U_{p, t}, \rho\left(R_{p, t}, U_{p, t}\right)=-0.0496$ is not statistically significant from zero, as the associated value or the t-test under the null hypothesis of $\rho\left(R_{p, t}, U_{p, t}\right)=0$ is -1.65 , establishing the statistical validity of the restriction imposed by Equation $(15)^{21}$. The F-stat for the equality of variances given by Equation (16), results in a test statistic value of 0.97 supporting the non-rejection of the null hypothesis of the equality of variances.

To test for the claim that the monthly returns $U_{p, t}$ of the arbitrage free portfolio are compensating for the existence of additional risk factors due to the inefficiency of the chosen benchmark we test for the relationship between the additional factors $\left(S M B_{t}\right.$ and $\left.H M L_{t}\right)$ and the returns $U_{p, t}$ by running a linear time-series regression of the form: $U_{p, t}=c_{o}+c_{1} S M B_{t}+c_{2} H M L_{t}+v_{p, t}$ where $v_{p, t}$ captures the random component of $U_{p, t}$. The results are presented in Table 2. These results suggest that

\footnotetext{
${ }^{20} \mathrm{We}$ also verify that the sum of the proportions that define the risk free portfolio is approximately equal to zero. It is not exactly zero because portfolio $p$ is not composed exclusively from the six portfolios.

${ }^{21}$ The value of the correlation between $R_{p, t}$ and $U_{p, t}$ is not exactly zero. Due to the condition $R_{m, t}=R_{p, t}$, portfolio $\mathrm{p}$ is not constituted exclusively from the six portfolios included in this example. 
there is a strong linear relationship between the chosen two risk factors and the returns $U_{p, t}$ that compensate for the inefficiency of the chosen benchmark.

Table 2: Relationship between $U_{p, t}$ and the risk factors $S M B_{t}$ and $H M L_{t}$ (1106 monthly observations, p-values are in parentheses)

\begin{tabular}{|c|c|}
\hline$c_{O}$ & Coefficient \\
\hline$c_{1}$ & $\begin{array}{c}-0.18592 \\
(0.00189)^{* * *}\end{array}$ \\
\hline $\begin{array}{c}0.44530 \\
(0.00000)^{* * *}\end{array}$ \\
\hline$c_{2}$ & $\begin{array}{c}0.24625 \\
(0.00000)^{* * *}\end{array}$ \\
\hline F-stat & 435.21 \\
\hline $\mathrm{R}^{2}$ & 0.4411 \\
\hline
\end{tabular}

*** Indicates significance at $1 \%$

To test for the equivalence of the predicted returns from our model, we start by conducting two statistical exercises. First, using predictions for Equation (21) and the linear three-factor model, Equation (25), we generate equilibrium/expected returns for each portfolio. Subsequently we test for the equality of mean returns against the alternative of significant differences, using the t-test.

In this exercise, we generate predicted returns using the coefficients from the three-factor model estimated above as follows, first, we set the values of the factors $S M B_{t}$ and $H M L_{t}$ to their averages whilst allowing the values of $R_{m, t}$ to vary through time, secondly, we calculate mean returns, over time, for each of the six portfolios and collect them in the series $\left(\bar{p}_{s}^{m}, s=1,2,3,4,5,6\right)$, where the super script $m$ indicates that the factors SMB and HML have been kept at their sample average values. We then compare each portfolio mean return to its mean return obtained using Equation (21), these are denoted as $\bar{p}_{s}^{u}, \mathrm{~s}=1,2,3,4,5,6$. Our theory suggests that these mean returns 
should be statistically identical, that is we test the null hypothesis $H_{0}: \bar{p}_{S}^{u}-\bar{p}_{s}^{m}=0$ against the alternative $H_{1}: \bar{p}_{s}^{u}-\bar{p}_{s}^{m} \neq 0$. The results from the test are presented in Table 3. We find that the mean differences of the two mean predictions for all six portfolios are zero, in support of the null hypothesis, with standard deviations not exceeding 0.4424 basis points.

Table 3: Mean prediction differences $\left\{\bar{p}_{s}^{u}-\bar{p}_{s}^{m}\right\}$, standard deviations and t-statistics, $H_{o}: \bar{p}_{s}^{u}-\bar{p}_{s}^{m}=0 \quad$ (SMB and HML set to mean values)

\begin{tabular}{|c|c|c|c|c|c|c|}
\hline & $\bar{p}_{1}^{u}-\bar{p}_{1}^{m}$ & $\bar{p}_{2}^{u}-\bar{p}_{2}^{m}$ & $\bar{p}_{3}^{u}-\bar{p}_{3}^{m}$ & $\bar{p}_{4}^{u}-\bar{p}_{4}^{m}$ & $\bar{p}_{5}^{u}-\bar{p}_{5}^{m}$ & $\bar{p}_{6}^{u}-\bar{p}_{6}^{m}$ \\
\hline $\begin{array}{c}\text { Mean } \\
\text { difference }\end{array}$ & 0.0000 & 0.0000 & 0.0000 & 0.0000 & 0.0000 & 0.0000 \\
\hline $\begin{array}{c}\text { Standard } \\
\text { deviation }\end{array}$ & 0.4424 & 0.2529 & 0.1486 & 0.1257 & 0.0868 & 0.3354 \\
\hline t-statistic & 0.0000 & 0.0000 & 0.0000 & 0.0000 & 0.0000 & 0.0000 \\
\hline
\end{tabular}

In the second testing exercise, we generate predicted portfolio mean returns by letting all three factors to vary through time, we calculate the mean returns $\left(\bar{p}_{s}^{3 f}\right)$, and we compare them to $\bar{p}_{s}^{u}$. This is a more stringent test as we allow all the factors in the three-factor model to vary through time.

Our results from this exercise, with the same null and alternative hypotheses, are presented in Table 4. We find that the average differences of the two means predicted returns for each of all six portfolios are not significantly different from zero. 
Table 4: Mean prediction differences $\left\{\bar{p}_{s}^{u}-\bar{p}_{s}^{3 f}\right\}$, standard deviations and t-statistics, $H_{0}: \bar{p}_{s}^{u}-\bar{p}_{s}^{3 f}=0 \quad($ SMB and HML vary through time)

\begin{tabular}{|c|c|c|c|c|c|c|}
\hline & $\bar{p}_{1}^{u}-\bar{p}_{1}^{3 f}$ & $\bar{p}_{2}^{u}-\bar{p}_{2}^{3 f}$ & $\bar{p}_{3}^{u}-\bar{p}_{3}^{3 f}$ & $\bar{p}_{4}^{u}-\bar{p}_{4}^{3 f}$ & $\bar{p}_{5}^{u}-\bar{p}_{5}^{3 f}$ & $\bar{p}_{6}^{u}-\bar{p}_{6}^{3 f}$ \\
\hline $\begin{array}{c}\text { Mean } \\
\text { difference }\end{array}$ & 0.0000 & -0.2676 & -0.2017 & 0.5390 & -0.0372 & -0.2290 \\
\hline $\begin{array}{c}\text { Standard } \\
\text { deviation }\end{array}$ & 3.4289 & 2.8481 & 4.2291 & 0.8546 & 1.1630 & 2.8711 \\
\hline t-statistic & 0.0000 & 0.0000 & 0.0000 & 0.0000 & 0.0000 & 0.0000 \\
\hline
\end{tabular}

Finally to test for the ability of our model to account for the data (observed portfolio returns) we calculate the two correlation coefficients between the actual returns and the predicted returns from each model, depicted by Equations (25) and (21), respectively, and test for their equality ${ }^{22}$. Let $\rho_{s}^{u}\left(p_{s, t}, p_{s, t}^{u}\right)$ be the correlation coefficient between the actual returns of portfolio $s$ and the returns of portfolio $s$ derived using our proposed methodology and $\rho_{s}^{m}\left(p_{s, t}, p_{s, t}^{m}\right)$ be the correlation coefficient between the actual returns of portfolio $s$ and the returns of portfolio $s$ derived using the three-factor model where we set the values of the factors $S M B_{t}$ and $H M L_{t}$ to their averages $(s=1,2,3,4,5,6)$. Tables 5 present the results for testing the equality of the correlation coefficients. The predicted/equilibrium portfolio returns from the two approaches are statistically indistinguishable as predicted by Corollary IV.1.

\footnotetext{
${ }^{22}$ To test for the equality of the correlation coefficients we use the statistic under the null hypothesis $\mathrm{H}_{0} \rho_{1}=\rho_{2}, z=(\hat{p} 1-\hat{p} 2) / 2 *[1 /(T-3)]^{0.5} \approx N(0,1)$ 
Table 5: Correlation coefficients $\rho_{s}^{u}\left(p_{s, t}, p_{s, t}^{u}\right), \rho_{s}^{m}\left(p_{s, t}, p_{s, t}^{m}\right)$ and z-statistics

\begin{tabular}{|l|c|c|c|c|c|c|}
\hline & $\rho_{1}^{u}, \rho_{1}^{m}$ & $\rho_{2}^{u}, \rho_{2}^{m}$ & $\rho_{3}^{u}, \rho_{3}^{m}$ & $\rho_{4}^{u}, \rho_{4}^{m}$ & $\rho_{5}^{u}, \rho_{5}^{m}$ & $\rho_{6}^{u}, \rho_{6}^{m}$ \\
\hline coefficient & 0.89, & 0.90, & 0.86, & 0.97, & 0.95, & 0.90, \\
& 0.89 & 0.90 & 0.86 & 0.97 & 0.95 & 0.90 \\
\hline z-statistic & 0.0000 & 0.0000 & 0.0000 & 0.0000 & 0.0000 & 0.0000 \\
\hline
\end{tabular}

Finally, let $\rho_{s}^{3 f}\left(p_{s, t}, p_{s, t}^{3 f}\right)$ be the correlation coefficient between the actual returns of portfolio $s$ and the returns of portfolio $s$ derived using the three-factor model where we allow all the factors to vary through time $(s=1,2,3,4,5,6)$. Table 6 presents the results for testing the correlation coefficients $\rho_{s}^{u}\left(p_{s, t}, p_{s, t}^{u}\right)$ and $\rho_{s}^{3 f}\left(p_{s, t}, p_{s, t}^{3 f}\right)$ for equality.

Table 6: Correlation coefficients $\rho_{s}^{u}\left(p_{s, t}, p_{s, t}^{u}\right), \rho_{s}^{3 f}\left(p_{s, t}, p_{s, t}^{3 f}\right)$, z-statistics (all factors are time varying)

\begin{tabular}{|l|c|c|c|c|c|c|}
\hline & $\rho_{1}^{u}, \rho_{1}^{3 f}$ & $\rho_{2}^{u}, \rho_{2}^{3 f}$ & $\rho_{3}^{u}, \rho_{3}^{3 f}$ & $\rho_{4}^{u}, \rho_{4}^{3 f}$ & $\rho_{5}^{u}, \rho_{5}^{3 f}$ & $\rho_{6}^{u}, \rho_{6}^{3 f}$ \\
\hline coefficient & 0.89, & 0.91, & $0.87,1.00$ & 0.98, & $0.95,0.97$ & 0.91, \\
& 0.99 & 0.99 & & 0.99 & & 0.98 \\
\hline z-statistic & $2.235^{* *}$ & $1.911^{*}$ & $3.032^{* * *}$ & 0.303 & 0.517 & 1.774 \\
\hline
\end{tabular}

$*, * *, * * *$ Indicate significance at $10 \%, 5 \%$ and $1 \%$ respectively

The averages of the correlation coefficients over all six portfolios are $\bar{\rho}_{s}^{u}\left(p_{s, t}, p_{s, t}^{u}\right)=0.918$ and $\bar{\rho}_{s}^{3 f}\left(p_{s, t}, p_{s, t}^{3 f}\right)=0.937$, respectively and we find no statistically significant difference between them

From both of these exercises we find that on average across a number of assets (6 portfolios) and time periods our proposed approach produces predicted returns almost indistinguishable from those generated by a well-established linear three-factor model. In this particular case the two approaches result in almost identical predictions regarding expected returns. 
The statistical evidence reported here supports the basic idea that the arbitrage free portfolio that compensates for the inefficiency of the benchmark in a given factor structure is a useful device to examine whether the relationship between the chosen factors and the returns $U_{p, t}$ of the arbitrage free portfolio are strongly associated. If such a relationship cannot be found, the validity of chosen factors could be questionable resulting in serious mispricing by underestimating the risk.

\section{Conclusions}

This study provides a common ground between the APM framework and the analysis of expected return-variance efficient or inefficient benchmarks in a given factor structure. The main emphasis of this study has been the analytic formulation of the relationship between a multi-factor APM and a linear pricing model based on a possibly undiversified inefficient benchmarks in a given factor structure. It has been demonstrated that a multi-factor APM reduces to a two-beta model for an undiversified multi-factor inefficient benchmark; one induced by the benchmark and one associated with its inefficiency (LBPUI). The potential advantage of this result is that we can use a multi-factor generating model to expand the LBPUI to a linear multifactor pricing model in which the inefficient part of the particular benchmark constitutes a helpful norm for selecting common factors that affect security returns.

This linear specification is based on the theoretical framework developed in this study as it results to a well-specified securities pricing model based on inefficient benchmarks. In addition, this model does not require the utilization of the market portfolio because it can be applied to subset of securities available in the market. Moreover, it provides additional insights into the nature of factors that affect expected returns on securities. It allows researchers after selecting risk factors to have a helpful norm justifying their selection. 
It is worth emphasizing that a multi-factor pricing model based on the LBPUI includes an observable premium related to a benchmark along with another computable factor premium related to the inefficiency of that benchmark. In this particular case, at least in theory, this multi-factor pricing model provides support for the continued existence of the security beta in relation to the benchmark despite its inefficiency.

In addition, we have shown that a multi-factor APM is equivalent to a single linear beta pricing model based on a multi-factor efficient benchmark (LBPDE) other than the GMVP. Formally, in the presence of a given multi-factor structure, this result produces a simple link among a multi-factor APM and the LBPDE.

The results from the empirical application are very encouraging. The return predictions from our model matched very closely (statistically identical) the estimates from the Fama-French three-factor model. More particularly, we have established that the returns from the arbitrage-free portfolio correspond closely the two additional to the inefficient benchmark risk factors. This result establishes the relevance of the factors accounting for the benchmark inefficiency. It is this statistical association that aids in selecting factors because the returns of the arbitrage free portfolio are acting as a substitute of the linear combination of only these factors that account for asset returns. 


\section{Appendix A:}

\section{Proof of the Relation between the Arbitrage Pricing Model and the LBPDE}

We begin with the following proposition:

Proposition A1: Let q be a well-diversified portfolio whose return can be expressed by a linear $K$-factor model, and $\mathbf{X}_{\mathbf{q}}^{\prime} \mathbf{u}=1, \mathbf{X}_{\mathbf{q}}$ is the $N \times 1$ vector defining portfolio q. Then, the $N \mathrm{x} 1$ vector of security expected returns is approximately linear to the $N \times 1$ unit vector and the $N$ x 1 vector of security betas:

$$
\mathbf{e} \approx h_{O} \mathbf{u}+h_{1} \mathbf{B}
$$

where $h_{o^{\prime}} h_{1}$ are constants, and $\mathrm{B}$ is the $N \times 1$ vector of security betas in relation to portfolio $q$.

\section{Proof}

Let $\mathrm{q}$ be a well-diversified portfolio with $\mathbf{X}_{\mathbf{q}}^{\prime} \mathbf{u}=1$. Next consider the $N \times 1$ vector of weights, call it vector $\mathbf{y}$, defining an arbitrage free portfolio. It is assumed that the arbitrage free portfolio includes one or more long and short positions. If this portfolio has no systematic risks due to the factors that affect its return, then it can be immediately written:

$$
\begin{gathered}
y^{\prime} \mathrm{u}=0 \\
\mathrm{y}^{\prime} \mathrm{B}_{1}=0, \mathrm{y}^{\prime} \mathrm{B}_{2}=0, \ldots, \mathrm{y}^{\prime} \mathrm{B}_{K}=0
\end{gathered}
$$

We can make use of Equations (1) and (4) (in the main text) to express the covariance between the returns on security $i$ and portfolio $q$ as follows:

$$
\operatorname{Cov}\left(R_{i}, R_{q}\right)=b_{i 1} b_{q 1} \sigma^{2}\left(f_{1}\right)+b_{i 2} b_{q 2} \sigma^{2}\left(f_{2}\right)+\ldots+b_{i K} b_{q K} \sigma^{2}\left(f_{K}\right)
$$

Dividing both sides of Equation (A3) by $\sigma^{2}\left(R_{q}\right)$ gives:

$$
\frac{\operatorname{Cov}\left(R_{i}, R_{q}\right)}{\sigma^{2}\left(R_{q}\right)}=b_{i 1} b_{q 1} \frac{\sigma^{2}\left(f_{1}\right)}{\sigma^{2}\left(R_{q}\right)}+b_{i 2} b_{q 2} \frac{\sigma^{2}\left(f_{2}\right)}{\sigma^{2}\left(R_{q}\right)}+\ldots+b_{i K} b_{q K} \frac{\sigma^{2}\left(f_{K}\right)}{\sigma^{2}\left(R_{q}\right)}
$$

Equation (A4) provides an expression of the security $i$ 's beta relative to portfolio $q$ in terms of $b_{i 1}, b_{i 2}, \ldots, b_{i K}$. 
Equation (A4) can be written in matrix notation as follows:

$$
\mathbf{B}=b_{q 1} \frac{\sigma^{2}\left(f_{1}\right)}{\sigma^{2}\left(R_{q}\right)} \mathrm{B}_{1}+b_{q 2} \frac{\sigma^{2}\left(f_{2}\right)}{\sigma^{2}\left(R_{q}\right)} \mathrm{B}_{2}+\ldots+b_{q K} \frac{\sigma^{2}\left(f_{K}\right)}{\sigma^{2}\left(R_{q}\right)} \mathrm{B}_{\mathrm{K}}
$$

where $\mathrm{B}$ is the $N \times 1$ vector of security betas in relation to portfolio $q$, and $\mathrm{B}_{1}, \mathrm{~B}_{2}, \ldots, \mathrm{B}_{\mathrm{K}}$ are the $N \times 1$ vectors of factor beta coefficients of the securities on each of the factors ${ }^{23}$. In essence Equation (A5) provides a linear decomposition of the beta of any security with respect to portfolio $q$ in terms of its betas with respect to the $K$ factors.

Pre-multiplying both sizes of (A5) by $\mathbf{y}^{\prime}$ and recognising the fact that the arbitrage free portfolio has zero systematic risks due to the factors that affect its return, yields (see Equation (A2)):

$$
y^{\prime} B=0
$$

Also since $\mathrm{e} \approx \lambda_{o} \mathrm{u}+\lambda_{1} \mathrm{~B}_{1}+\lambda_{2} \mathrm{~B}_{2}+\ldots+\lambda_{\kappa} \mathrm{B}_{\mathrm{K}}$ this arbitrage free portfolio has zero expected return. We know that $\mathbf{y}^{\prime}$ is orthogonal to the unit vector $\mathbf{u}$, the vector of security betas $\mathbf{B}$ and the vector of expected returns $\mathbf{e}$. Thus, the expected return vector can be represented approximately as a linear combination of $\mathbf{u}$ and $\mathbf{B}$ :

$$
\mathrm{e} \approx h_{o} \mathbf{u}+h_{1} \mathbf{B}
$$

where $h_{O}, h_{1}$ are constants.

In view of Proposition A1, it is established that the expected security returns can be expressed as approximate linear functions of their betas estimated with respect to a well-diversified benchmark, even though each security's return is generated by a $K-$ factor model. In this case, the multi-factor pricing model is approximately reduced to a single-beta linear pricing relation.

Exploring further Equation (A7) let $\mathrm{V}$ be the positive definite $N$ x $N$ covariance matrix of returns, based on a structure of a multi-factor framework. Next, using Equation (A7) as an exact relationship, it would be desirable to express the vector of security returns as follows:

$$
\mathrm{e}=h_{o} \mathrm{u}+h_{1} \frac{\mathrm{VX}}{\sigma^{2}\left(R_{q}\right)}
$$

${ }^{23}$ If we assume that $\mathrm{V}$ is a non-singular, then Equation (A5) gives:

$$
X_{q}=V^{-1}\left[b_{q 1} \sigma^{2}\left(f_{1}\right) \mathrm{B}_{1}+b_{q 2} \sigma^{2}\left(f_{2}\right) \mathrm{B}_{2}+\ldots+b_{q 2} \sigma^{2}\left(f_{k}\right) \mathrm{B}_{\mathrm{K}}\right] \text {. }
$$


where $\sigma^{2}\left(R_{q}\right)=\mathbf{X}_{q}^{\prime} \mathbf{V X}$ is the variance of the multi-factor, well-diversified portfolio $q$.

Let $E\left(R_{z q}\right)$ be the expected return of a multi-factor, well-diversified portfolio whose return is uncorrelated with the return of portfolio $q^{24}$. Then, pre-multiplying Equation (A8) by the $N$ x 1 vector of proportions that defines the zero-beta portfolio yields $E\left(R_{z q}\right)=h_{o}$. A pre-multiplication of the equation $\mathbf{e}=E\left(R_{z q}\right) \mathrm{u}+h_{1} \frac{\mathrm{VX}_{\mathrm{q}}}{\sigma^{2}\left(\mathrm{R}_{\mathrm{q}}\right)}$ by $\mathbf{X}_{\mathbf{q}}^{\prime}$ results in $E\left(R_{q}\right)-E\left(R_{z q}\right)=h_{1}$. Therefore, Equation (A8) can be written as:

$$
\mathbf{e}=E\left(R_{z q}\right) \mathbf{u}+\left[E\left(R_{q}\right)-E\left(R_{z q}\right)\right] \frac{\mathbf{V X}}{\sigma^{2}\left(R_{q}\right)}
$$

It should be emphasized that in Equation (A9), the covariance matrix $V$ has a specific structure because it is produced using a security return generating model.

Equation (A9) can be used to express $\mathbf{X}_{\mathbf{q}}$ as follows:

$$
\mathrm{X}_{\mathrm{q}}=\frac{\mathrm{V}^{-1} \mathrm{e}-E\left(R_{z q}\right) \mathrm{V}^{-1} \mathrm{u}}{E\left(R_{q}\right)-E\left(R_{z q}\right)} \sigma^{2}\left(R_{q}\right)
$$

Following these preliminary considerations, a corollary that expresses the returns of the zero-beta portfolio is presented.

Corollary A1 If $q$ is a well-diversified benchmark in a given factor structure, then the expected return of $E\left(R_{z q}\right)$ is given by:

$$
E\left(R_{z q}\right)=\frac{a-E\left(R_{q}\right) b}{b-E\left(R_{q}\right) c}
$$

where $\mathrm{a}=\mathrm{e}^{\prime} \mathrm{v}^{-1} \mathrm{e}, \mathrm{b}=\mathrm{e}^{\prime} \mathrm{v}^{-1} \mathrm{u}$, and $\mathrm{c}=\mathrm{u}^{\prime} \mathrm{v}^{-1} \mathrm{u}$.

\section{Proof}

Pre-multiplying Equation (A10) by the transposed unit vector $u^{\prime}$ gives:

\footnotetext{
${ }^{24}$ Roll (1980) provided properties of orthogonal portfolios in an expected return-standard deviation framework. Lehmann $(1987,1992)$ offered discussions of the role of orthogonal portfolios in asset pricing.
} 


$$
1=\frac{\mathrm{u}^{\prime} \mathrm{V}^{-1} \mathbf{e}-E\left(R_{z q}\right) \mathrm{u}^{\prime} \mathrm{V}^{-1} \mathrm{u}}{E\left(R_{q}\right)-E\left(R_{z q}\right)} \sigma^{2}\left(R_{q}\right)
$$

A pre-multiplication of Equation (A10) by the transposed vector of expected returns e' provides:

$$
E\left(R_{q}\right)=\frac{\mathrm{e}^{\prime} \mathrm{V}^{-1} \mathrm{e}-E\left(R_{z q}\right) \mathrm{e}^{\prime} \mathrm{V}^{-1} \mathrm{u}}{E\left(R_{q}\right)-E\left(R_{z q}\right)} \sigma^{2}\left(R_{q}\right)
$$

Making use of Equations (A12) and (A13), yields the following:

$$
E\left(R_{q}\right)=\frac{a-E\left(R_{z q}\right) b}{b-E\left(R_{z q}\right) c}
$$

Finally, Equation (A14) produces Equation (A11).

At this point, it is necessary to note that Equation (A11) holds for any multi-factor, well-diversified minimum variance portfolio except for the GMVP because it has an expected return equal to $\frac{b}{c}$ (Roll 1977).

Next, the following corollary derives the weights of a multi-factor, well-diversified benchmark.

Corollary A2 In a market without arbitrage opportunities, the $N \mathrm{x} 1$ vector of proportions defining a well-diversified benchmark $q$ in a given factor structure can be written as follows:

$$
\mathbf{X}_{\mathbf{q}}=\frac{\mathrm{a}-b E\left(R_{\mathbf{q}}\right)}{\mathrm{a} c-b^{2}} \mathbf{V}^{-1} \mathbf{u}-\frac{b-c E\left(R_{q}\right)}{\mathrm{a} c-b^{2}} \mathbf{V}^{-1} \mathbf{e}
$$

\section{Proof}

Solving Equation (A13) for $\sigma^{2}\left(R_{q}\right)$ we find:

$$
\sigma^{2}\left(R_{q}\right)=\frac{E\left(R_{q}\right)\left(E\left(R_{q}\right)-E\left(R_{z q}\right)\right)}{a-E\left(R_{z q}\right) b}
$$

A combination of Equations (A10) and (A16) gives:

$$
\mathrm{X}_{\mathrm{q}}=\frac{\mathrm{v}^{-1} \mathbf{e}-E\left(R_{z q}\right) \mathrm{V}^{-1} \mathrm{u}}{\mathrm{a}-E\left(R_{\mathrm{zq}}\right) b} E\left(R_{q}\right)
$$


After using Equations (A17) and (A11) and simplifying the resulting equation, the portfolio weights of the multi-factor efficient benchmark $q$ are given by Equation (A15).

Basically Corollary A2 shows that the well-diversified benchmark $q$ in a given factor structure is also a minimum variance benchmark in the given factor structure.

Equation (A15) is designed to capture the linear relationship between the vector of the investment proportions that define the multi-factor minimum variance portfolio $q$ and its expected return.

The following Corollary shows the equivalence of a linear $K$-factor model and the linear relation between security's expected returns and betas calculated against a welldiversified benchmark in a given factor structure (LBPDE).

Corollary A.3 Consider a perfectly competitive and frictionless market containing $N$ securities, where short sales of securities are permitted and there are no arbitrage opportunities. It is assumed that investors homogeneously believe that the singleperiod random return of any of the $\mathrm{N}$ securities can be generated by a linear K-factor model. Let $\mathrm{V}$ be a non-singular positive definite covariance matrix, and assume that there are at least two securities with different expected returns. Then, the following three propositions are equivalent ${ }^{25}$ :

(i) There is an exact relation between the vector of expected security returns and the $K$ vectors of factor betas:

$$
\mathrm{e}=\lambda_{o} \mathrm{u}+\lambda_{1} \mathrm{~B}_{1}+\lambda_{2} \mathrm{~B}_{2}+\ldots+\lambda_{K} \mathrm{~B}_{\mathrm{K}}
$$

where $\mathrm{B}_{1}, \mathrm{~B}_{2}, \ldots, \mathrm{B}_{\mathrm{K}}$ are the $\mathrm{N} \mathrm{x} 1$ vectors of factor beta coefficients of the securities on the K factors. Also, there is a well-diversified benchmark $q$ (has no idiosyncratic risk) in the given factor structure.

(ii) The vector of expected security returns can also be expressed as follows:

$$
\mathbf{e}=E\left(R_{z q}\right) \mathbf{u}+\left[E\left(R_{q}\right)-E\left(R_{z q}\right)\right] \mathrm{B}
$$

where $q$ is a well-diversified benchmark with expected return greater than that of the GMVP ${ }^{26}, \mathbf{X}_{\mathrm{q}}^{\prime} \mathrm{u}=1, \mathrm{~B}$ is the $\mathrm{N} \times 1$ vector of security betas in relation to $q$, and $E\left(R_{\mathrm{Zq}}\right)$ is the expected return of a well-diversified minimum variance portfolio whose return is uncorrelated with the return of $q^{27}$.

\footnotetext{
${ }^{25}$ Chamberlain (1983) considered a riskless security and offered some bounds on the approximation error in the arbitrage pricing equation. Then he showed that these bounds imply the equivalence between an exact arbitrage pricing and a well-diversified mean-variance efficient portfolio.

${ }^{26}$ Here GMVP is excluded since it produces beta equal to one on all securities, Roll (1977)..

${ }^{27}$ Chen (1983) ascertained that an exact multi-beta pricing model can always be reduced to a relation between expected return and beta through performing an appropriate transformation of the factors. Dybvig and Ross (1985) showed mathematically that the CAPM and the existence of a multi-factor security return generated model produces the APM. Grinblatt and Titman (1987) considered a risk-free
} 
(iii) The well-diversified benchmark $q$ is a minimum variance benchmark in the given factor structure

Proof

(i) $\rightarrow$ (ii) Assume the validity of Equation (A18). Let $q$ be a well-diversified portfolio in a given factor structure defined by the $\mathrm{N}$ x 1 vector $\mathrm{X}_{\mathbf{q}}$ of proportions invested in its risky securities, where $\mathbf{X}_{\mathbf{q}}^{\prime} \mathbf{u}=1$. Following a proof similar to Proposition A1 we derive Equation (A19).

(ii) $\rightarrow$ (iii) Consider a well-diversified portfolio $q$ in a given factor structure with $\mathbf{X}_{\mathrm{q}}^{\prime} \mathbf{u}=1$. We assume the validity of Equation (A19). Then the portfolio $q$ is a multifactor efficient portfolio in the expected return-standard deviation space (there is a similar proof as that from Roll (1977), Corollary 6, p.165).

(iii) $\rightarrow$ (i) Consider a multi-factor well-diversified efficient portfolio $q$ in a given factor structure. Then the $N$ x 1 vector of expected returns can be expressed with the aid of Equation (A9).

Equation (A5) holds since $q$ is a well-diversified portfolio. Substituting Equation (A5) into Equation (A9) allows us to compute the vector of security expected return as follows:

$$
\mathbf{e}=E\left(R_{z q}\right) \mathbf{u}+\left[E\left(R_{q}\right)-E\left(R_{z q}\right)\right]\left[b_{q 1} \frac{\sigma^{2}\left(f_{1}\right)}{\sigma^{2}\left(R_{q}\right)} \mathbf{B}_{1}+\ldots+b_{q k} \frac{\sigma^{2}\left(f_{k}\right)}{\sigma^{2}\left(R_{q}\right)} \mathbf{B}_{\mathbf{K}}\right]
$$

\footnotetext{
asset, $\mathrm{N}$ securities having a nonsingular covariance matrix and defined a set of $K$ reference portfolios, where $K \leq N$, to be a collection of $K$ portfolios such that any combination of these portfolios is different than the GMVP. Then they proved that an exact linear pricing holds with respect to the $K$ reference portfolios if and only if a linear combination of these $K$ portfolios lies on the mean-variance frontier (Proposition 1, p. 100). The portfolio $q$ presented in our work needs only to be a well-diversified portfolio in a given factor structure. Huberman, Kandel and Stambaugh (1987) considered a set of mimicking portfolios and they proved that there exists only one portfolio of mimicking portfolios on the minimumvariance frontier, where this portfolio is other than the GMVP, if and only if an exact arbitrage pricing equation is valid.
} 
Equation (A20) can be also written as:

$$
\mathrm{e}=\lambda_{o} \mathrm{u}+\lambda_{1} \mathrm{~B}_{1}+\lambda_{2} \mathrm{~B}_{2}+\ldots+\lambda_{K} \mathrm{~B}_{\mathrm{K}}
$$

where $E\left(R_{z q}\right)=\lambda_{o}$ and $\lambda_{k}=\left[E\left(R_{q}\right)-E\left(R_{z q}\right)\right] b_{q k} \frac{\sigma^{2}\left(f_{k}\right)}{\sigma^{2}\left(R_{q}\right)}, k=1,2, \ldots, K$.

The LBPDE shown in Equation (A19) highlights that the security expected return vector is a linear and exact function of the vector of security betas. Here, it is important to note that even though a security's return is generated by a $\mathrm{K}$-factor model, its expected return can always be expressed as a linear function of its beta estimated with respect to a multi-factor, well-diversified benchmark. Thus, the multifactor APM can be contracted into a single beta-expected return relationship ${ }^{28}$.

It is apparent that the LBPDE does not hold for all types of expected return-standard deviation efficient portfolios, which the LBPE model does. It holds only for specific efficient benchmarks with returns satisfying a $K$-factor return generating model, being well-diversified and being comprised of securities, each of which satisfies a multi-factor $\mathrm{APM}^{29}$.

Essentially, Corollary A.3 establishes a simple link between the multi-factor APM and the LBPDE. In other words, it shows that in a market without arbitrage opportunities where an exact multi-factor APM holds, a well-diversified portfolio, other than the GMVP, is also a minimum variance portfolio in the given multi-factor structure. Conversely, if there are no arbitrage opportunities, then a well-diversified minimum variance portfolio whose return is generated by a $K$-factor linear model implies an exact APM.

As a final thought, consider a universe of investment opportunities containing all possible securities. On the one hand, if there are no arbitrage opportunities and Equation (A18) holds for each possible security, then an exact relation between expected returns and security betas can be produced by following the procedure presented. This relationship is identical to the classical CAPM, which is derived from the market portfolio efficiency in the space of expected return and standard deviation. On the other hand, if the market portfolio is a well-diversified efficient portfolio in a given factor structure, a multi-factor APM can be derived using an equilibrium argument. Nevertheless, it is impossible to identify all securities and their compositions in the market portfolio, and thus the corresponding multi-factor APM or the CAPM cannot be empirically tested. In fact, this is the same critique as that of Roll (1977) for the capital asset pricing model. However, the results provided in

\footnotetext{
${ }^{28}$ Trzcinka (1986) showed that the number of statistical estimated factors increases with the size of the sample, but the first factor remains dominant.

${ }^{29}$ A similar result holds in the expected return-variance framework. Namely, consider a large number of securities, the efficient frontier of these securities and an efficient benchmark, call it $q$, other than the GMVP. Suppose that the single index model holds for a well-diversified portfolio, call it $s$, using the the return of the efficient benchmark $q$ as the independent variable. Then portfolio $s$ lies on the line drawn from the expected return of the zero-beta portfolio to $q$ that passes tangent to the efficient frontier at the point $\left(E\left(R_{q}\right), \sigma\left(R_{q}\right)\right)$. In this case the LBPE holds for portfolio $s$.
} 
Corollary A3 can be used to illustrate the relationship between a multi-factor APM and the CAPM. 


\section{Appendix B:}

\section{Proof of the Relation between the Arbitrage Pricing Model and the LBPUI}

Proof of $\operatorname{Cov}\left(R_{q}, U_{p}\right)=0$

After making use of Equations (4) and (12) in the main text we get:

$$
\operatorname{Cov}\left(R_{q}, R_{p}\right)=\operatorname{Cov}\left(E\left(R_{q}\right)+b_{q 1} f_{1}+\ldots+b_{q K} f_{K^{\prime}} E\left(R_{p}\right)+b_{p 1} f_{1}+\ldots+b_{p K} f_{K}+\varepsilon_{p}\right)
$$

Taking into account the assumptions of the return generating model, Equation (B1) implies:

$$
\operatorname{Cov}\left(R_{q}, R_{p}\right)=b_{q 1} b_{p 1} \sigma^{2}\left(f_{1}\right)+\ldots+b_{q K} b_{p K} \sigma^{2}\left(f_{K}\right)
$$

Next, one can employ Equation (4) to obtain (where q is a well-diversified portfolio):

$$
\sigma^{2}\left(R_{q}\right)=b_{q 1}^{2} \sigma^{2}\left(f_{1}\right)+\ldots+b_{q K}^{2} \sigma^{2}\left(f_{K}\right)
$$

Thus, substituting Equations (B2) and (B3) into Equation (7) after some straightforward algebraic manipulation yields:

$$
b_{q 1}\left(b_{p 1}-b_{q 1}\right) \sigma^{2}\left(f_{1}\right)+\ldots+b_{q K}\left(b_{p K}-b_{q k}\right) \sigma^{2}\left(f_{K}\right)=0
$$

Also holds

$$
\begin{aligned}
& \operatorname{Cov}\left(R_{q}, U_{p}\right)=\operatorname{Cov}\left(E\left(R_{q}\right)+b_{q 1} f_{1}+\ldots+b_{q K} f_{K^{\prime}}, U_{p}\right)= \\
& b_{q 1} \operatorname{Cov}\left(U_{p^{\prime}} f_{1}\right)+\ldots+b_{q K} \operatorname{Cov}\left(U_{p^{\prime}} f_{K}\right)
\end{aligned}
$$

Utilizing the return generating model for $U_{p}$ (Equation (14)) into Equation (B5) and taking into account Equation (9) gives:

$$
\operatorname{Cov}\left(R_{q}, U_{p}\right)=b_{q 1} \operatorname{Cov}\left(\left(b_{p 1}-b_{q 1}\right) f_{1}, f_{1}\right)+\ldots+b_{q K} \operatorname{Cov}\left(\left(b_{p K}-b_{q k}\right) f_{K}, f_{K}\right)
$$

From Equations (B6) and (B4) it follows that 


$$
\operatorname{Cov}\left(R_{q}, U_{p}\right)=b_{q 1}\left(b_{p 1}-b_{q 1}\right) \sigma^{2}\left(f_{1}\right)+\ldots+b_{q K}\left(b_{p K}-b_{q k}\right) \sigma^{2}\left(f_{K}\right)=0
$$

\section{Proof of Corollary III.1}

Equation (17) can be written in matrix form as follows:

$$
V X_{p}=V X_{q}+h_{p}
$$

where $h_{p}=$ the $N$ x 1 vector of covariances between the security returns and the residual term $U_{p}$.

Using Equation (A15) into Equation (B7) and solving the resulting equation for $\mathrm{X}_{\mathrm{p}}$ provides Equation (18).

\section{Proof of Corollary IV.1}

(i) $\rightarrow$ (ii) Suppose Equation (19) is valid. Consider a multi-factor inefficient and not well diversified benchmark $p$ and a multi-factor well-diversified efficient benchmark $q$ with $E\left(R_{p}\right)=E\left(R_{q}\right)$. Then a combination of Equations (A5) and (B7) can be used to derive:

$$
\frac{\mathrm{VX}_{\mathrm{p}}-\mathrm{h}_{\mathrm{p}}}{\sigma^{2}\left(R_{q}\right)}=b_{q 1} \frac{\sigma^{2}\left(f_{1}\right)}{\sigma^{2}\left(R_{q}\right)} \mathrm{B}_{1}+b_{q 2} \frac{\sigma^{2}\left(f_{2}\right)}{\sigma^{2}\left(R_{q}\right)} \mathrm{B}_{2}+\ldots+b_{q k} \frac{\sigma^{2}\left(f_{k}\right)}{\sigma^{2}\left(R_{q}\right)} \mathrm{B}_{\mathrm{K}}
$$

Let $\mathbf{y}$ be a $N$ x 1 vector of weights defining an arbitrage free portfolio. If this portfolio has no systematic risks due to the factors that influence its return, then making use of Equations (A2) and (B8) the following equation is obtained:

$$
\mathbf{y}^{\prime}\left[\frac{\mathrm{VX}_{\mathrm{p}}-\mathrm{h}_{\mathrm{p}}}{\sigma^{2}\left(R_{q}\right)}\right]=0
$$

Next, noting that $\mathbf{y}^{\prime} \mathbf{e}=0$ (from Equations (19), $\mathbf{y}^{\prime} B_{k}=0, k=1,2, \ldots, K$ ), $\mathbf{y}^{\prime} \mathbf{u}=0$ where $\mathrm{u}$ is $N \times 1$ unit matrix, and taking into account Equation (B9) it can be written: 


$$
\mathbf{e}=\delta_{1} \mathrm{u}+\delta_{2}\left[\frac{\mathrm{VX} \mathbf{p}^{-h_{p}}}{\sigma^{2}\left(R_{q}\right)}\right]
$$

where $\delta_{1}, \delta_{2}$ are constants.

We will now compute the constants $\delta_{1}, \delta_{2}$. Let $\mathrm{X}_{\mathbf{z q}}$ be an $N$ x 1 vector of weights that defines the orthogonal minimum variance portfolio of $q$. Then $\mathbf{X}_{\mathbf{z q}}^{\prime} \mathrm{VX}_{\mathbf{q}}=0$ or $X_{z q}^{\prime}\left(N X_{p}-h_{p}\right)=0$. So pre- multiplying Equation (B10) by $X_{z q}^{\prime}$ gives $\delta_{1}=E\left(R_{z p}\right)$. In this case Equation (B10) can be expressed as:

$$
e=E\left(R_{z p}\right) \mathrm{u}+\delta_{2}\left[\frac{\mathrm{VX}_{\mathrm{p}}-\mathrm{h}_{\mathrm{p}}}{\sigma^{2}\left(R_{q}\right)}\right]
$$

Pre-multiplying Equation (B11) by $X_{q}^{\prime}$ and using Equation (16) we take:

$$
E\left(R_{q}\right)=E\left(R_{z p}\right)+\delta_{2}
$$

or

$$
E\left(R_{p}\right)=E\left(R_{z p}\right)+\delta_{2}
$$

Finally, a combination of Equations (B11) and (B13) gives Equation (20).

(ii) $\rightarrow$ (i) Assume that Equation (20) is true. After utilizing Equations (1), (12) and (14) the following equations hold:

$$
\mathrm{VX} \mathrm{p}_{\mathrm{p}}=b_{p 1} \sigma^{2}\left(f_{1}\right) \mathrm{B}_{1}+\ldots+b_{p k} \sigma^{2}\left(f_{k}\right) \mathrm{B}_{\mathrm{K}}+\boldsymbol{\varepsilon}
$$

and

$$
\mathrm{h}_{\mathrm{p}}=b_{U p 1} \sigma^{2}\left(f_{1}\right) \mathrm{B}_{1}+\ldots+b_{U p K} \sigma^{2}\left(f_{k}\right) \mathrm{B}_{\mathrm{K}}+\varepsilon
$$

where $\varepsilon=$ the $\mathrm{N} \times 1$ vectors with elements $\operatorname{Cov}\left(\varepsilon_{i}, \varepsilon_{p}\right), i=1,2,3, \ldots, N$. 
Equations (B14) and (B15) can be substituted into Equation (20) leading to:

$\mathbf{e}=E\left(R_{\mathrm{zp}} \boldsymbol{\mu}+\left[E\left(R_{p}\right)-E\left(R_{z p}\right)\right]\left[\left(b_{p 1}-b_{U p 1}\right) \frac{\sigma^{2}\left(f_{1}\right)}{\sigma^{2}\left(R_{q}\right)} \mathbf{B}_{1}+\ldots+\left(b_{p K}-b_{U p K}\right) \frac{\sigma^{2}\left(f_{K}\right)}{\sigma^{2}\left(R_{q}\right)} \mathbf{B}_{\mathbf{K}}\right]\right.$

After using Equation (9) Equation (B16) becomes:

$$
\mathrm{e}=\lambda_{o} \mathrm{u}+\lambda_{1} \mathrm{~B}_{1}+\ldots+\lambda_{\kappa} \mathrm{B}_{\mathrm{K}}
$$

where $E\left(R_{z p}\right)=\lambda_{o}$ and $\lambda_{k}=\left[E\left(R_{p}\right)-E\left(R_{z p}\right)\right] b_{q k} \frac{\sigma^{2}\left(f_{k}\right)}{\sigma^{2}\left(R_{q}\right)}, k=1,2, \ldots, K$. 


\section{References}

Black, F., M. C. Jensen, and M. Scholes (1972), The capital asset pricing model: Some empirical tests, in: M. Jensen, ed., Studies in the theory of capital markets, (Praeger Publishers, Inc., New York), 79-121.

Blume, M. E., and I. Friend (1973), A new look at the capital asset pricing model, Journal of Finance, 28, 19-33.

Chamberlain, S. G. (1983), Funds, factors and diversification in arbitrage pricing models, Econometrica, 51, 1305-1323.

Chamberlain, G., and M. Rothschild (1983), Arbitrage, factor structure, and meanvariance analysis on large assets markets, Econometrica, 51, 1281-1304.

Chan, L. K. C., Y. Hamao, and J. Lakonishok (1991), Fundamentals and stock returns in Japan, Journal of Finance, 46, 1739-1764.

Chen, N. F., and J. Ingersoll (1983), Exact pricing in linear factor models with infinitely many assets: A note, Journal of Finance, 38 , 985-988.

Connor, G. (1984), A Unified beta pricing theory, Journal of Economic Theory, 34 $13-31$.

Connor, G., and R. Korajczyk (1988), Risk and return in equilibrium APT:

Application of a new test methodology, Journal of Financial Economics, 21, 255-290.

Diacogiannis, G (1999), A three-dimensional risk-return relationship based upon the inefficiency of a portfolio: Derivation and implications, The European Journal of Finance,5, 225-235.

Diacogiannis, G., and D. Feldman (2013), Linear beta pricing with inefficient benchmarks, Quarterly Journal of Finance, 3, 1350004 1-35.

Dybvig, P. (1983), An explicit bound on individual assets' deviation from APT pricing in a finite economy, Journal of Financial Economics, 12, 483-496.

Dybvig, P. H., and S. A. Ross (1985), Yes the APT is testable, Journal of Finance, 40, 1173-1188.

Ehrhardt, M. C. (1987), A mean-variance deviation of a multi-factor equilibrium model, Journal of Financial and Quantitative Analysis, 22, 227-236.

Fama, E. (1977), Foundations of Finance, Basic Books, New York.

Fama, E. F. (1996) Multifactor portfolio efficiency and multifactor asset pricing, Journal of Financial and Quantitative Analysis, 31, 441-465.

Fama, E. F., and J.D. MacBeth (1973), Risk, Return and Equilibrium: Empirical 
Tests, Journal of Political Economy, 81, 607-636.

Ferguson, M. F., and R. L. Shockley (2003), Equilibrium anomalies, Journal of Finance, 58, 2549-2580.

Ferson, W. E., and A. F. Siegel (2001), The efficient use of conditioning information in portfolios, Journal of Finance, 56, 967-982.

Ferson, W. E., A. F. Siegel, and P. Xu (2006), Mimicking portfolios with conditioning information, Journal of Financial and Quantitative Analysis, 41, 607635.

Fletcher, J. (1994), The mean-variance efficiency of benchmark portfolios: UK evidence, Journal of Banking and Finance, 18, 673-685.

Gibbons, M. R. (1982), Multivariate test of financial models: A new approach, Journal of Financial Economics, 10, 3-27.

Gibbons, M. R., S. A. Ross, and J. Shanken (1989), A test of the efficiency of a given portfolio, Econometrica, 57, 1121-1152.

Green R. (1986), Benchmark portfolio inefficiency and deviations from the security market line, Journal of Finance, 41, 295-312.

Green, C. J. (1990), Asset demands and asset prices in UK: Is there a risk premium. Manchester School of Economics and Social Studies, 58.

Grinblatt, M., and S. Titman (1983), Factor pricing in a finite economy, Journal of Financial Economics, 12, 497-508.

Grinblatt, M., and S. Titman (1987), The relation between mean-variance efficiency and arbitrage pricing, Journal of Business, 60, 97-112.

Hansen, L. P., and S. F. Richard (1987), The role of conditioning information in deducing testable restrictions implied by dynamic asset pricing models, Econometrica, 55, 587-614.

Hawawini, G. (1993), Market efficiency and equity pricing: International evidence and implication for global investing, In D.K. Das (ED.) International Finance, Contemporary Issues, London and New York.

Huberman, G. (1982), A simple approach to arbitrage pricing theory, Journal of Economic Theory, 28, 183-191.

Huberman, G., and Z. Wang (2005), Arbitrage pricing theory, The new Palgrave dictionary of economics, 2nd edition, edited by L. Blume and S. Durlauf (London: Palgrave Macmillan). 
Huberman, G., S. Kandel, and R. F. Stambaugh (1987), Mimicking portfolios and exact arbitrage pricing, Journal of Finance, 42, 1-9.

Ingersoll, J. (1984), Some results in the theory of arbitrage pricing, Journal of Finance, 39, 1021-1039.

Jagannathan, R., (1996), Relation between the slopes of the conditional and unconditional mean-standard deviation frontiers of asset returns, in Modern Portfolio Theory and Its Applications, Inquiries into Valuation problems, Saito, S., Sawaki, K. and Kubota, K, editors, 1-8, Center for Academic Societies, Osaka, Japan.

Jobson, J. D. and B. Korkie, (1982), Potential performance and tests of portfolio efficiency, Journal of Financial Economics, 10, 433-466.

Jobson, J. D., and B. Korkie (1985), Some tests of linear asset pricing with multivariate normality, Canadian Journal of Administrative Sciences, 2, 114-138.

Kandel, S., and R.F. Stambaugh, (1987), On correlations and inferences about meanvariance efficiency, Journal of Financial Economics, 18, 61-90.

Kandel, S., and R. F. Stambaugh, (1989), A mean variance framework for tests of asset pricing modes, Review of Financial Studies, 2, 125-156.

Kim, M. K., and C. Wu (1987), Macro-economic factors and stock returns, The Journal of Financial Research, 10, 87-98.

Lehmann, B. N. (1987), Orthogonal frontiers and alternative mean variance efficiency tests, Journal of Finance, 42, 601-619.

Lehmann, B. N. (1992), Empirical testing of asset pricing models in: P. Newman, M. Milgate and J. Eatwell, eds., the new palgrave dictionary of money and finance, Stockton Press, NY, 749-759.

Lehmann, B. N., and D. Modest (1988), The Empirical Foundation of the Arbitrage Pricing Theory. Journal of Financial Economics, 21, 213-254.

Mackinlay, A. G. , and M. P. Richardson (1991), Using generalised methods of moments to test mean-variance efficiency, Journal of Finance, 46, 511-527.

Naranjo, A., M. Nimalendran, and M. Ryngaert (1998), Stock Returns, Dividend yield and taxes, Journal of Finance, 53, 2029-2057.

Roll, R. (1977), A critique of the asset pricing theory's tests Part I: On past and potential testability of the theory, Journal of Financial Economics, 4, 129-176.

Roll, R. (1980), Orthogonal portfolios, Journal of Financial and Quantitative Analysis, $15,1005-1023$.

Roll, R., and S. A. Ross (1994), On the cross sectional Relation between expected returns and betas, Journal of Financial Economics, 49, 101-121. 
Ross, S. A. (1976a), The arbitrage theory of capital asset pricing, Journal of Economic Theory, 13, 341-360.

Ross, S. (1976b), Risk, return and arbitrage, Risk Return in Finance ed. I. Friend and J. Bicksler, Cambridge, Mass.: Ballinger.

Ross, S. (1977), The capital asset pricing model (CAPM) short selling restrictions and related issues, Journal of Finance, 32, 177-183.

Ross, S. A., and M. M. Walsh (1983), A simple approach to the pricing of risky assets with uncertain exchange rates, Research in International Business and Finance, 3, 3954 .

Shanken, J. (1985), Multivariate tests of the zero-beta CAPM, Journal of Financial Economics, 14, 327-348.

Shanken, J. (1987), Multivariate proxies and asset pricing relations: Living with Roll's critique, Journal of Financial Economics, 18, 91-110.

Shanken, J. (1996), Statistical methods in tests of portfolio efficiency: A Synthesis, In: G.S. Maddala and C.R. Rao (eds.), Handbook of Statistics 14: Statistical Methods in Finance, 693 - 711, North-Holland.

Sharpe, W. F. (1977), The capital asset pricing model: A multi-beta interpretation, in: H. Levy and M. Sarnat, eds, Financial Decision Making under Uncertainty, Academic Press, New York.

Solkin, B. H. (1983), International arbitrage pricing theory, Journal of Finance, 38, 449-457.

Stambaugh, R. (1982), On the exclusion of assets from tests of the two parameter model: A sensitivity analysis, Journal of Financial Economics, 10, 237-268.

Trzcinka, C. (1986), On the number of the factors in the Arbitrage Pricing Model, Journal of Finance, 41, 347-368.

Wei, K. C. J. (1988), An Asset-pricing theory unifying the CAPM and APT, Journal of Finance, 43, 881-892.

Zhou, G. (1991), Small sample tests of portfolio efficiency, Journal of Financial Economics, 30, 165-191. 
